\title{
GRITOS DE UN MUNDO DESCONOCIDO: UNA APROXIMACIÓN A LA MUERTE VIOLENTA DE MENORES A TRAVÉS DE LA JURISPRUDENCIA ${ }^{1}$
}

\author{
José Antonio Ramos Vázquez \\ Profesor contratado doctor de Derecho penal \\ Universidad de A Coruña
}

\section{Introducción}

\author{
«(...) O neno non conoce a morte; \\ mais ás veces chéganos un berro \\ dun mundo desconocido pra o home (...)». \\ Luis Pimentel, «Os nenos» ${ }^{2}$.
}

El poeta Luis Pimentel se pregunta en un poema distinto del que encabeza este trabajo «¿de dónde viene la muerte para los niños?» ${ }^{3}$. Pimentel, médico de profesión, conocía de primera mano las altas tasas de mortalidad infantil de su época y el drama íntimo que esto suponía a nivel familiar y social.

Lo cierto es que el poético interrogante sigue estando vigente a día de hoy: la tasa global de mortalidad infantil ha descendido radicalmen-

1 Este trabajo se enmarca dentro de las actividades de mi grupo de investigación, «Criminalidad y Justicia Penal en el siglo XXI» (ECRIM), actividades que están financiadas por la Ayuda para la consolidación y estructuración de unidades de investigación competitivas del Sistema universitario de Galicia (referencia: GRC2015/021), concedida por la Consellería de Cultura, Educación y Ordenación Universitaria de la Xunta de Galicia (IP: Patricia Faraldo Cabana).

2 Pimentel, L., Obra completa, Galaxia, Vigo, 2009, p. 48.

3 Pimentel, Obra completa, cit., p. 93. 
te en España en las últimas décadas ${ }^{4}$, pero sigue presente en nuestra sociedad la ominosa sombra de la muerte violenta de menores, cuyas cifras y dinámicas resultan, a mi juicio, tan difíciles de analizar como potencialmente alarmantes, visto que en otros Estados que nos llevan décadas de ventaja en interés criminológico por este tema se ha concluido que el primer año de vida es, con mucho, el grupo de edad con mayor tasa de victimización por homicidio ${ }^{5}$ y que el Instituto Nacional de Estadística recoge como «Agresión (homicidio)» la causa de fallecimiento de cerca de 400 menores de edad en el período aquí estudiado (2000-2016) ${ }^{6}$.

Dicho lo anterior, y a salvo de lo que más adelante diré sobre la metodología de este trabajo, debo señalar que mi interés por este asunto quiénes son los menores que mueren violentamente en España y quiénes les producen la muerte- procede de la introducción en el Código penal, a través de la Ley Orgánica 1/2015, de 30 de marzo, de la agravante (común a homicidio y asesinato) de "que la víctima sea menor de dieciséis años de edad». La nula justificación que el legislador dio a dicha introducción (como si el mayor merecimiento de pena $-\mathrm{o}$, mejor dicho, el merecimiento de una mayor pena- en estos casos fuese algo apodíctico) y la severidad extrema de la consecuencia jurídica que lleva aparejada esta conducta (nada menos que la prisión permanente revisable en el caso del asesinato - que, por otra parte, como indicaré más adelante, constituye la inmensa mayoría de supuestos) me llevaron a preguntarme por cuáles habrían de ser los grupos de casos destinados a tan severo castigo, teniendo como hipótesis la de que se acabaría por castigar, fundamentalmente, a progenitores.

4 De acuerdo con los datos del Banco Mundial, en los últimos 20 años, la tasa de mortalidad infantil (por cada 1.000 nacidos vivos) se redujo a la mitad (2,8 en 2015 - 5,5 en 1995). Si echamos la vista atrás otros 20 años, nos encontramos con 16,5 niños muertos por cada 1.000 nacidos vivos en 1975 (https://datos.bancomundial.org/ indicator/SP.DYN.IMRT.IN?locations=ES - Fecha de última consulta: 30 de diciembre de 2017).

5 Así, con referencia a Inglaterra y Gales, Vid. Brookman, F. / Nolan, J., "The Dark Figure of Infanticide in England and Wales: Complexities of Diagnosis», en Journal of Interpersonal Violence, 21 (7), 2006, p. 869 y ss., quienes señalan que «los niños de menos de un año tienen al menos el doble de probabilidades de ser víctimas de un homicidio que cualquier otro grupo de edad (...). En concreto, tienen una tasa de victimización de 6,3 por cada 100.000, en comparación con el 3,3 de las personas de 24 años (la segunda edad con mayor tasa de victimización)» (Vid. Brookman / Nolan, «The Dark Figure of Infanticide», cit., p. 870, añadiendo - con abundante bibliografía— que esta sobrevictimización de los niños en muertes violentas existe también en otros Estados, como Canadá, Australia o los Estados Unidos).

$6 \mathrm{http}: / /$ www.ine.es/dyngs/INEbase/es/operacion.htm?c=Estadistica_C\&cid=1254736 176780\&menu=resultados\&idp $=1254735573175-$ Fecha de última consulta: 30 de diciembre de 2017. Indico que son cerca de 400 menores, pues el INE subdivide los datos en tramos de edades, uno de los cuales es de 15 a 19 años, de modo que es imposible desglosar en este último tramo cuántos de los fallecidos eran aún menores de edad y cuántos ya no, siendo la cifra total de 404. 


\section{Gráfico 1. Número de personas de 0 a 19 años cuya causa registrada de fallecimiento es "Agresión (homicidio)».}

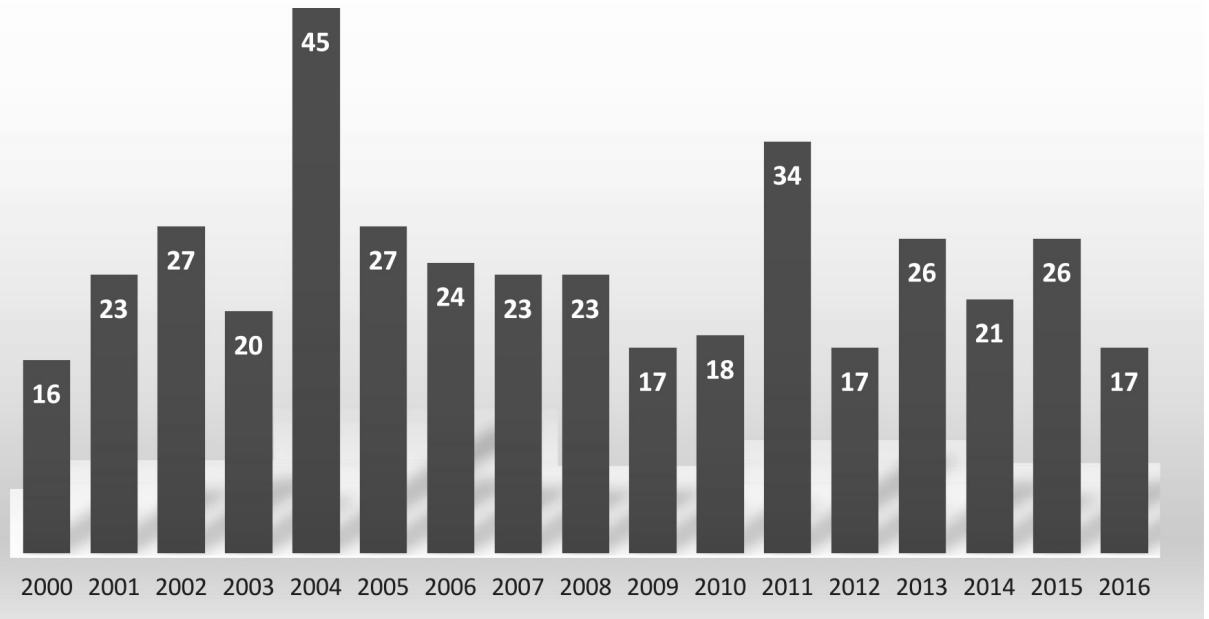

Fuente: INE.

Meses más tarde, se renovó mi interés por la realidad criminológica de la muerte violenta de menores en nuestro Estado, al rebufo del debate político y mediático sobre la vinculación entre violencia de género y violencia contra los hijos de las mujeres que la sufren (y, en concreto, sobre la conveniencia de privar a los hombres acusados por violencia de género del régimen de visitas respecto de sus hijos menores, por el riesgo de que lleven a cabo actos de violencia frente a éstos).

Creo que ambas cuestiones - quiénes van a ser los destinatarios prioritarios de la prisión permanente revisable ${ }^{7}$, de un lado, y si existe un fuerte vínculo entre violencia de género y muerte de menores, de otro- justifican, aun con sus deficiencias, el interés del presente estudio.

7 Pues la hipótesis de asesinato de un menor de 16 años es la conducta estadísticamente más probable de todas aquéllas a las que el CP reserva dicha pena. De hecho, la primera condena a prisión permanente revisable que se ha impuesto en nuestro Estado lo ha sido por el asesinato de dos menores y es una de las sentencias aquí estudiadas (sentencia de la Audiencia Provincial de Pontevedra de 14 de julio de 2017). 


\section{Metodología}

Uno de los problemas más graves que debe afrontar quien investiga el fenómeno de la causación dolosa de la muerte a menores es el de los datos.

En primer lugar, porque se considera generalmente que existe una importante cifra negra de homicidio/asesinato de menores, muchas veces enmascarada de muerte natural ${ }^{8}$ (y, en particular, en el caso de los recién nacidos, de síndrome de muerte súbita infantil ${ }^{9}$ ).

Desconozco, por mis evidentes carencias de formación en materia pediátrica/forense, hasta qué punto la causación intencional de la muerte a un menor es «más fácilmente disfrazable de accidente o de síndrome de muerte súbita» ${ }^{10}$ que a un adulto, ni mucho menos me aventuraría a plantear una hipótesis sobre la cientificidad del mencionado síndrome, de modo que me limitaré a enunciar la existencia del debate al respecto, y llamar la atención del lector sobre el hecho de que el INE recoge la muerte súbita infantil como causa de muerte de nada menos que 1.087 menores de edad ${ }^{11}$ en el período aquí estudiado (2000-2016) ${ }^{12}$.

En segundo lugar, aparte del problema mencionado en la nota 6, hay que señalar que el INE ofrece unos datos de fallecimientos de menores por causa «Agresión (homicidio)» que extrae del Boletín Estadístico de Defunción Judicial, boletín que «está dirigido a obtener la información de los fallecidos por causas que requieren una intervención judicial por haber indicios de posible causa accidental o violenta» ${ }^{13}$. Lógicamente, esto supone el nada desdeñable problema de la imposibilidad de saber

8 En especial, de niñas recién nacidas. Vid., en este sentido, la Resolución del Parlamento Europeo, de 8 de octubre de 2013, «Genericidio: ¿dónde están las mujeres que faltan?» (http://www.europarl.europa.eu/sides/getDoc.do?type=TA\&reference=P7-TA2013-0400\&language=ES\&ring=A7-2013-0245\#def_1_11 —Fecha de última consulta, 29 de diciembre de 2017).

9 Estudios realizados en otros Estados cifran el porcentaje de falsas diagnosis de dicho síndrome (y, consecuentemente, el porcentaje no apreciado de homicidios/asesinatos) en casi un 5\% para los Estados Unidos (McClain, P. / Sacks, J. / FroehlKe, R. / Ewigman, B., "Estimates of fatal child abuse and neglect: United States, 1979-88», en Pediatrics, 91, 1993, pp. 338 y ss.) y entre un 10 y un $20 \%$ en Reino Unido (EMERY, J. L., "Child abuse, sudden infant death syndrome, and unexpected infant death», en American Journal of Diseases of Children, 147 (10), 1993, pp. 1097 y ss.). Sobre el síndrome de muerte súbita infantil como diagnóstico apto para encubrir muertes violentas, Vid. GoldENBERG, C. L., "Sudden infant death syndrome as a mask for murder: investigating and prosecuting infanticide», en Southwestern University Law Review, 28, 1999, p. 599 y ss.

10 Bauman, C. A., "Rethinking the unthinkable: A study of child homicides», en Criminal Reports, 5. ${ }^{\text {a }}$ época, 8, 1997, p. 139.

${ }_{11}$ Fundamentalmente, aunque no en exclusiva, menores de 1 año.

$12 \mathrm{http}: / /$ www.ine.es/dyngs/INEbase/es/operacion.htm?c=Estadistica_C\&cid=1254736 $176780 \&$ menu $=$ resultados\&idp $=1254735573175 \ldots$ Fecha de última consulta: 30 de diciembre de 2017.

${ }^{13} \mathrm{http}: / /$ www.ine.es/daco/daco42/sanitarias/metodologia_00.pdf —Fecha de última consulta: 30 de diciembre de 2017. 
cuántos de esos casos indiciariamente computados como de homicidio han podido acreditarse, a la postre, como tales muertes violentas ${ }^{14}$.

\section{Gráfico 2. Número de personas cuya causa registrada de fallecimiento es «Síndrome de muerte súbita infantil».}

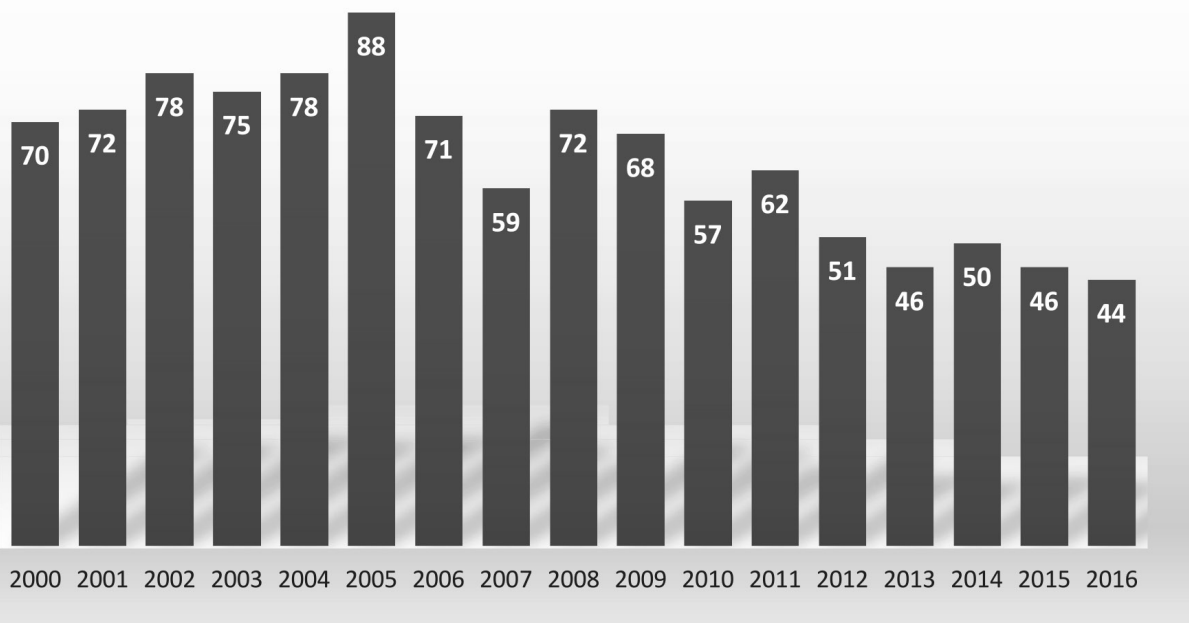

Fuente: INE.

Como es lógico, el único modo jurídicamente impecable de considerar acreditado un homicidio doloso o asesinato de un menor es hacerlo con sentencias condenatorias en la mano. Ello, además, implica una ventaja adicional: la de proveer al investigador de multitud de datos sobre el autor de los hechos y las circunstancias en las que se produjeron. Pero este método, a su vez, conlleva obvias limitaciones: en primer lugar, porque si se trata de un homicidio seguido de suicidio de su autor, difícilmente se habrá llegado a una sentencia ${ }^{15}$; en segundo lugar, por la siempre posible falta de exhaustividad de las bases de datos jurisprudenciales.

${ }^{14}$ Otro tanto sucede con otras estadísticas (por ejemplo, las del desaparecido Centro Reina Sofía para el estudio de la violencia sobre «menores asesinados por sus padres» o las del Ministerio de Sanidad sobre «menores víctimas mortales por violencia de género») que tienen como fuente atestados policiales o noticias aparecidas en medios de comunicación.

15 Salvo que, por ejemplo, se trate de una coautoría, como sucede en una de las sentencias analizadas en este trabajo (la de la Audiencia Provincial de Almería 241/2005, de 24 de octubre), en la que se condena a tres personas y se hace mención a una cuarta que se suicidó tras los hechos. 
Ante esta tesitura, la de optar por el dato numérico en bruto (que poco o nada nos dice sobre el fenómeno en sí) o por la jurisprudencia (con el riesgo de tomar como un todo lo que bien pudiera ser sólo una parte de la casuística global), he preferido lo segundo ${ }^{16}$, con las salvedades y consideraciones siguientes:

- Las sentencias aquí estudiadas han sido localizadas a través de sucesivas cadenas de texto en las bases de datos Tirant on line y Westlaw (Aranzadi) ${ }^{17}$, abarcando todos los órganos jurisdiccionales españoles ${ }^{18}$ y el período 2000-2016. Este período lo es de los hechos y no de las sentencias, de modo que, inevitablemente, habrá hechos de los últimos años cuya resolución judicial no haya recaído aún.

- Se han excluido las muertes por atentado terrorista ${ }^{19}$ (por afectar indiscriminadamente a un grupo de personas y, por tanto, no buscarse específicamente la muerte de menores). Se han incluido, no obstante, algunas sentencias en las que la edad de la víctima supone un elemento irrelevante o, incluso, aleatorio, como después referiré.

- Se han excluido las condenas por imprudencia grave (fundamentalmente, homicidios preterintencionales). Se han incluido, en cambio, las muertes por dolo eventual y en comisión por omisión.

- Se han excluido los hechos sobre las que hubiese recaído sentencia absolutoria en última instancia por falta de prueba sobre la existencia del delito o la participación del acusado, con independencia de que hubiese recaído sentencia condenatoria en primera instancia.

- Se han incluido, en cambio, aquellas sentencias absolutorias que lo hayan sido por aplicación de alguna eximente; es decir, aquellas sentencias en las que, a pesar de la absolución, se acredita que la persona juzgada ha matado dolosamente al menor.

${ }^{16}$ En la línea del primero (salvo error u omisión) de los trabajos publicados en España sobre esta cuestión: COMPANY, A. / PAJón, L. / Romo, J. / SORIA, M. A, «Filicidio, infanticidio y neonaticidio: estudio descriptivo de la situación en España entre los años 2000-2010», en Criminalidad, 57 (3), 2015, pp. 91 y ss.

17 Esta búsqueda ha sido llevada a cabo, bajo mi dirección, por Laura Fernández García, adjudicataria de una beca de colaboración en departamentos universitarios del Ministerio de Educación y Marta Guizán Roca, adjudicataria de una beca de colaboración de la Universidad de A Coruña en formación complementaria en los departamentos universitarios de los centros propios. La ayuda que ambas me han prestado en la localización del material jurisprudencial y la sistematización de su contenido ha sido crucial en la elaboración de este trabajo.

${ }_{18}$ Con las consabidas limitaciones en lo que a la jurisdicción de menores respecta.

19 Recuérdese que en los atentados de marzo de 2004 en Madrid fallecieron 10 personas de hasta 19 años, lo que, por otra parte, podría explicar que dicho año haya sido, con mucho, aquél en el que más muertes por «Agresión (homicidio)» se han registrado en lo que llevamos de siglo XXI (Vid. Gráfico 1). 
El resultado que ha arrojado la búsqueda es de 64 menores muertos. Qué porcentaje supongan respecto del total de menores fallecidos violentamente en el período analizado es, como he apuntado antes, difícil de averiguar. En todo caso, considero que sirven como punto de partida para entender mejor qué hay detrás de este fenómeno, de ese mundo aún en parte desconocido de la muerte de menores.

Hago mías, pues, las palabras de KAPLAN, quien, en su trabajo sobre madres que abandonan o matan a sus recién nacidos, señala que «el valor del presente estudio no estriba en su precisión matemática, sino, más bien, en que proporciona un portal de observación a un fenómeno ampliamente invisible para la opinión pública, (...) retratando más un bosque que un árbol concreto» ${ }^{20}$.

\section{Los datos recabados}

Con independencia de que el lector pueda por sí mismo tener una vista panorámica de los principales datos de las sentencias recabadas, a través de los cuadros que se adjuntan como anexo al presente estudio, se exponen a continuación los principales datos que se pueden extraer de aquéllas.

\subsection{Las víctimas}

La muestra analizada aquí está constituida por un total de 84 sentencias, que dan cuenta - como señalaba antes- de 64 menores fallecidos y otros 32 que consiguieron sobrevivir a un intento de asesinato/homicidio.

Como en otros Estados, los menores fallecidos antes del primer año de vida son amplia mayoría respecto a cualquier otra edad: algo más del $20 \%$ de todos los menores muertos. Si observamos las tentativas, la cifra es aún mayor (cerca del 38\%).

Eso sí (y sobre esto volveré más adelante): hay una clara variable de género en estas muertes, puesto que en 21 de 25 casos de niños de menos de un año fallecidos o sobre los que se ha llevado a cabo una tentativa de asesinato/homicidio (es decir, nada menos que el 84\% de los casos) la autora es una mujer (en concreto, veinte madres y una abuela).

Por otra parte, si subdividimos por tramos de edad, apreciaremos que el número de menores fallecidos es inversamente proporcional a

${ }^{20}$ Kaplan, D. S., "Who are the mothers who need Safe Haven Laws? An empirical investigation of mothers who kill, abandon, or safely surrender their newborns», en Wisconsin Journal of Law, Gender \& Society, 29, 2014, p. 449. 
su edad ${ }^{21}$, mientras que, en el caso de las tentativas, el tramo de 13 a 17 años es el que tiene mayor tasa de victimización (siempre por detrás de los menores de 1 año).

\section{Gráfico 3. Número de menores fallecidos, de acuerdo con la muestra jurisprudencial, divididos por tramos de edad.}

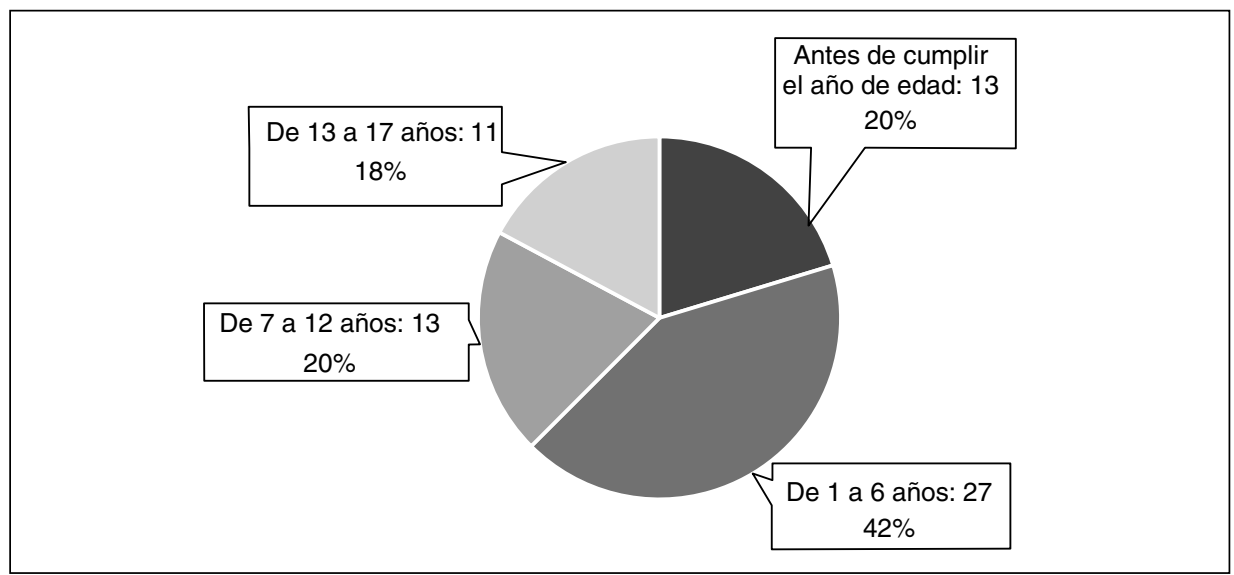

Fuente: Elaboración propia.

Gráfico 4. Número de menores víctimas de intento de homicidio/asesinato, de acuerdo con la muestra jurisprudencial, divididos por tramos de edad.

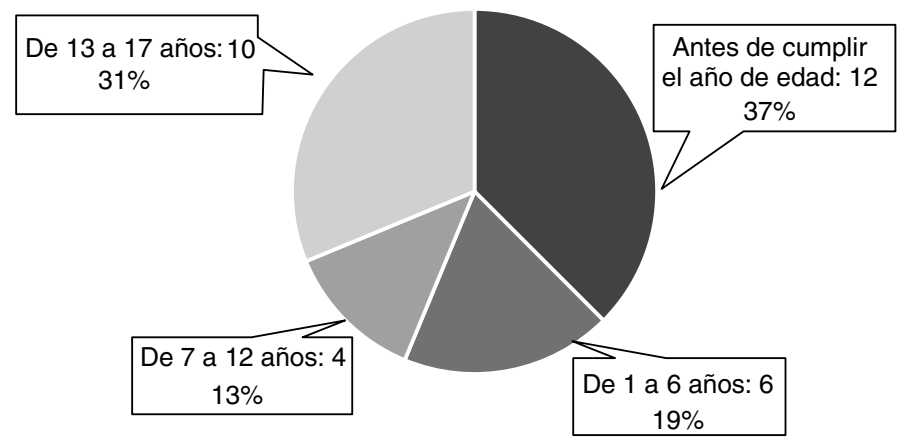

Fuente: Elaboración propia.

21 Obsérvese que los tramos en que he subdividido las edades son quinquenales, mientras que el año de vida es categoría individual, de modo que, aun habiendo más menores de entre 1 y 6 años fallecidos, son los primeros 12 meses de vida la anualidad en la que más muertes se dan. 


\subsection{Los autores}

Los otros protagonistas de este estudio son, por descontado, aquellas personas que llevaron a cabo la muerte (o el intento de dar muerte) a los menores.

Antes de desglosar los datos, conviene hacer una precisión, por más que pueda parecer obvia: en los supuestos en los que se castiga como coautoría (y no a un interviniente como autor y a otro como partícipe) dos conductas, una activa y una omisiva ${ }^{22}$, se contabiliza a ambos intervinientes como autores ${ }^{23}$. Naturalmente, sucede lo mismo si se trata de una coautoría en la que ambos intervinientes llevan a cabo una conducta activa. Y, naturalmente también, hay supuestos en los que una única persona mata a varios menores. Todo ello explica la discordancia entre el número de menores referidos en el apartado anterior y el número de autores que se examinan en éste.

Dicho lo anterior, entre los muchos modos posibles de clasificación de los autores, me han parecido de particular interés los siguientes:

En primer lugar, nos encontramos con 41 mujeres autoras y 51 casos en los que el autor es un hombre.

\section{Gráfico 5. Autores de los hechos, de acuerdo con la muestra jurisprudencial, divididos por sexo.}

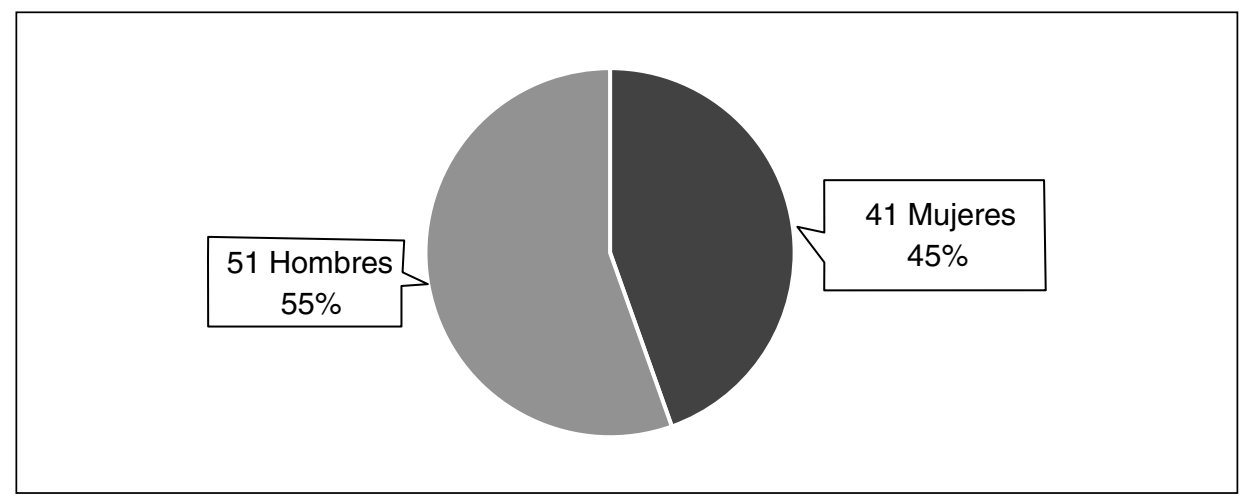

Fuente: Elaboración propia.

22 Siempre que haya habido, al menos, dolo eventual en el omitente, en consonancia con las premisas de la investigación, antes apuntadas.

${ }^{23}$ Sentencias de este tipo (que condenan a una persona que mata por acción a un menor y a otra persona como autora por omisión del mismo delito) hemos encontrado cinco. En cuatro de ellas es el padre de la víctima (o la pareja de la madre) quien lleva a cabo la acción y la madre quien es condenada por no evitar el resultado letal, siendo justo al revés (padre condenado por un delito de homicidio doloso en comisión por omisión por no haber evitado que la madre matase a la hija en común) en la quinta restante. 
En segundo lugar, conviene hacer una distinción crucial entre familiares ${ }^{24}$ y no familiares, siendo amplia mayoría (casi dos tercios) los autores que tienen relación de parentesco con la víctima.

\section{Gráfico 6: Autores de los hechos, de acuerdo con la muestra jurisprudencial, divididos por su relación de parentesco o no con el menor-víctima.}

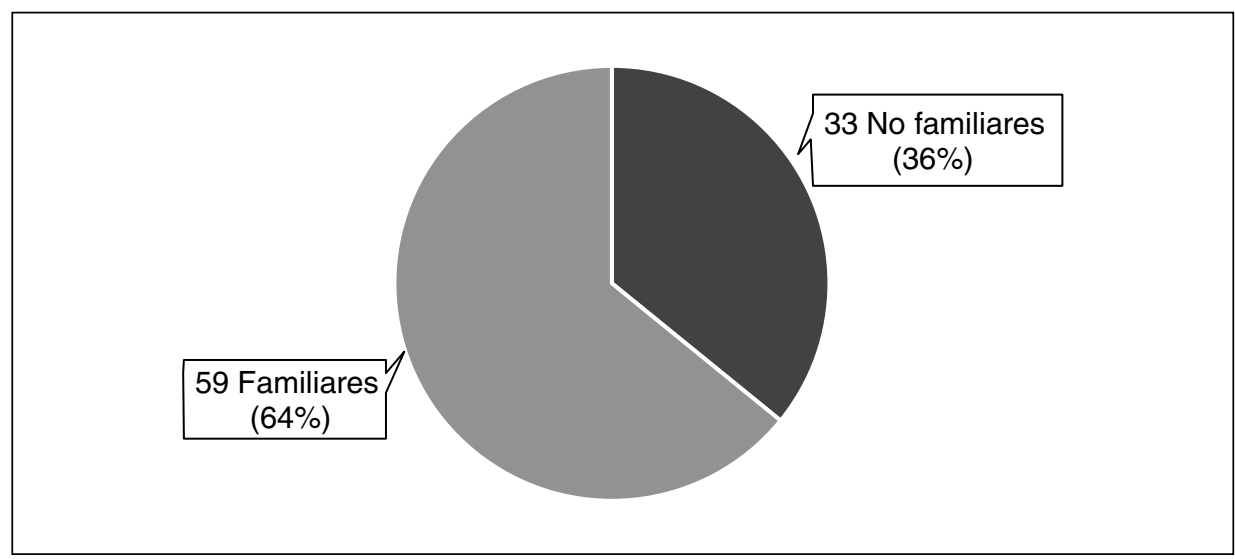

Fuente: Elaboración propia.

En tercer lugar, si cruzamos ambas variables (sexo del autor, por un lado, y parentesco o no respecto del menor, por otro), nos encontramos con una de las características más acusadas del fenómeno aquí estudiado (o, al menos, de esa porción del fenómeno que la muestra jurisprudencial nos deja entrever): la inmensa mayoría de autores que no tienen relación de parentesco con la víctima son hombres, mientras que, en el ámbito familiar, son mayoría las mujeres que matan (o intentan matar) a los menores.

De hecho, las madres biológicas son, con mucho, la categoría relacional más abundante, representando no sólo un 58\% de los familiares que matan o intentan matar a menores, sino también más de un tercio del total de autores (familiares o no).

Por su parte, en la categoría "no familiares», destacan las parejas de las madres (la cuarta parte del total), si bien nos encontramos con una variada casuística (desde peleas entre bandas juveniles a robos que acaban con la muerte del menor, pasando por la mera aleatoriedad - persona bajo un brote psicótico que ataca a todo el que se encuentra, p. ej.).

${ }^{24}$ En sentido estricto. Es decir, excluyendo parejas (presentes o pasadas) de alguno de los progenitores o de la propia víctima. 
Gráfico 7: Autores de los hechos, de acuerdo con la muestra jurisprudencial, que son parientes del menor víctima, divididos por sexo.

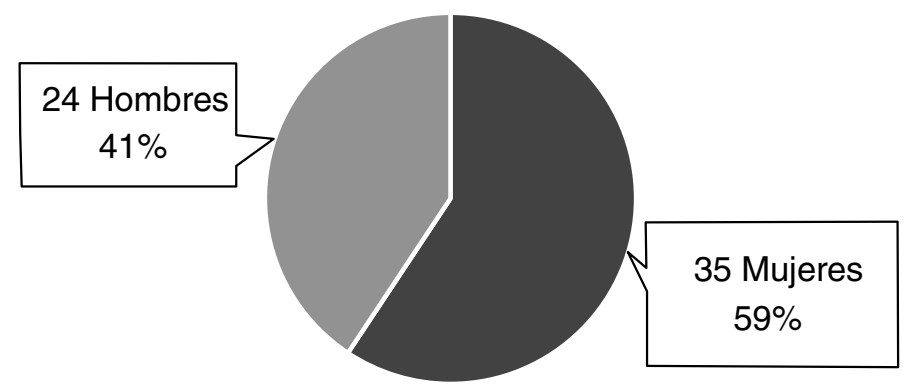

Fuente: Elaboración propia.

Gráfico 8: Autores de los hechos, de acuerdo con la muestra jurisprudencial, que no son parientes del menor víctima, divididos por sexo.

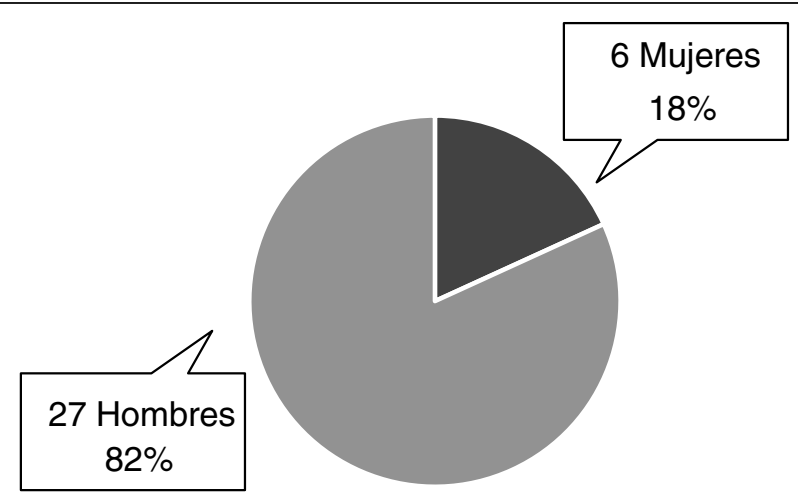

Fuente: Elaboración propia. 
Gráfico 9: Autores de los hechos, de acuerdo con la muestra jurisprudencial, que son familiares del menor víctima, divididos por su parentesco.

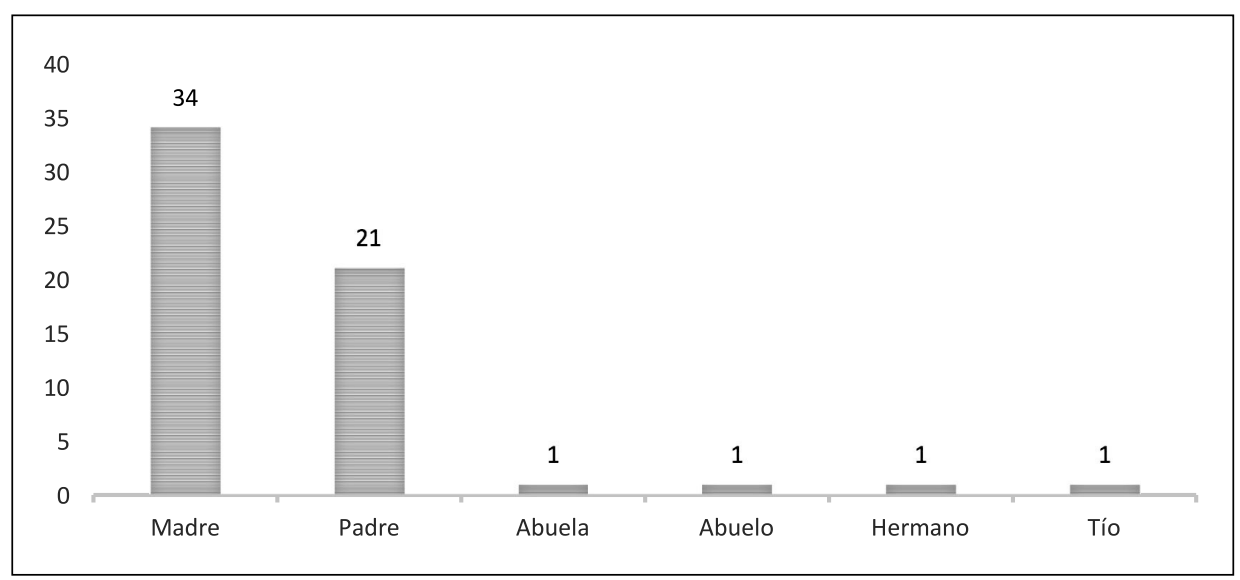

Fuente: Elaboración propia.

Gráfico 10. Autores de los hechos, de acuerdo con la muestra jurisprudencial, que no son familiares del menor víctima, divididos por su relación con éste.

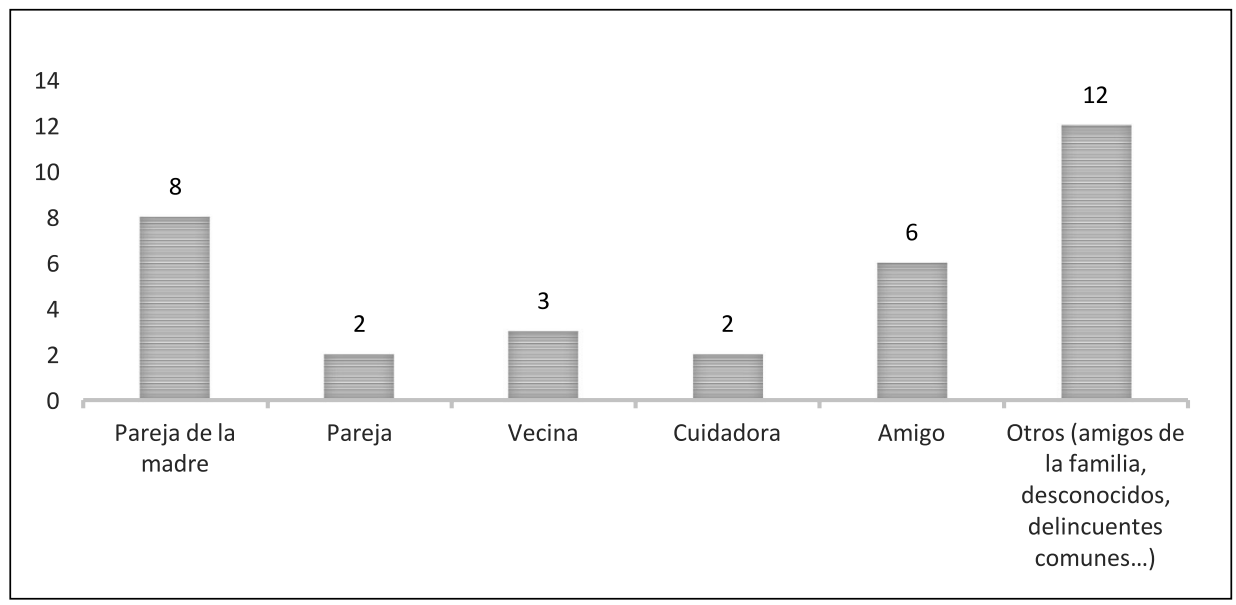

Fuente: Elaboración propia. 


\subsection{Muerte de menores y violencia en la pareja}

Como señalaba al comienzo de este trabajo, uno de mis intereses en analizar el rastro que las muertes de menores han dejado en nuestra jurisprudencia es el de comprender hasta qué punto existe una conexión con la violencia de género.

De las sentencias recabadas se infiere meridianamente dicha conexión: 13 de los 29 padres biológicos (o parejas de la madre biológica) que han matado a sus hijos (o hijos de su pareja), lo han hecho, según se acredita judicialmente, en un contexto de violencia de género; entendiendo por éste tanto la existencia de episodios previos de maltrato hacia la mujer (o, incluso, su homicidio), como la violencia vicaria hacia aquélla mediante el daño infligido a sus hijos ${ }^{25}$.

A este hecho, el de que casi la mitad de los homicidios/asesinatos de menores cometidos por padres/parejas de la madre hayan sido llevados a cabo en contextos de violencia contra la mujer, hay que unir el de que dos menores fallecidas lo fueron a manos de sus propias parejas.

Por último, merece, a mi juicio, destacarse el hecho de que existe la situación inversa: madres que, por celos, en un contexto de crisis de pareja, o por venganza hacia sus parejas masculinas acaban con la vida de los hijos en común. Por supuesto, se trata de casos menos frecuentes que los de la hipótesis inversa, pero suponen un porcentaje en absoluto desdeñable (4 madres sobre 34; casi un 12\%).

En suma, en algo más de la cuarta parte de los casos recogidos en la muestra jurisprudencial en que un padre/pareja de la madre o una madre matan o intentan matar a un menor, hay un trasfondo de violencia entre los miembros de la pareja que acaba por afectar a los menores.

En cambio, y me parece también un dato a tener en cuenta, la existencia de previos antecedentes penales en los padres/parejas de la madre que matan a un hijo/hijo de su pareja no puede decirse que sea usual (y, cuando existen, muchas veces no son por delitos violentos). En concreto, concurren antecedentes penales previos en un $27 \%$ de dicha clase de autores (o no concurren en un 73\% de ellos, en función de cómo se quiera enfocar este dato).

25 Así lo hace también el Ministerio de Sanidad en su estadística (cuya fuente es policial) de menores muertos por violencia de género, cifrándolos en 23 en el período 2013-2017:

(http://www.violenciagenero.msssi.gob.es/violenciaEnCifras/victimasMortales/fichaMenores/home.htm -Fecha de última consulta: 3 de enero de 2018). 


\subsection{Las decisiones judiciales: calificación jurídica $y$ circunstancias}

En la introducción a este trabajo, comentaba, asimismo, que me interesaba analizar la cuestión de la muerte dolosa de menores en nuestra jurisprudencia para constatar quiénes iban a ser los destinatarios prioritarios de la prisión permanente revisable. Ello supone partir de la premisa de que la muerte dolosa de menores constituye casi siempre, a juicio de la jurisprudencia, un supuesto de asesinato (pues en caso de que se califique como homicidio no cabrá imponer la antedicha pena).

Y así es, en efecto: en un $85 \%$ de las sentencias (tanto de tentativas como de consumaciones) se califican los hechos como de asesinato, por considerarse alevosa la muerte de niños, en cuanto que víctimas «naturalmente indefensas» ${ }^{26}$.

\section{Gráfico 11. Apreciación de eximentes o atenuantes relacionadas con la situación psicológica, a madres autoras de los hechos, de acuerdo con la muestra jurisprudencial.}

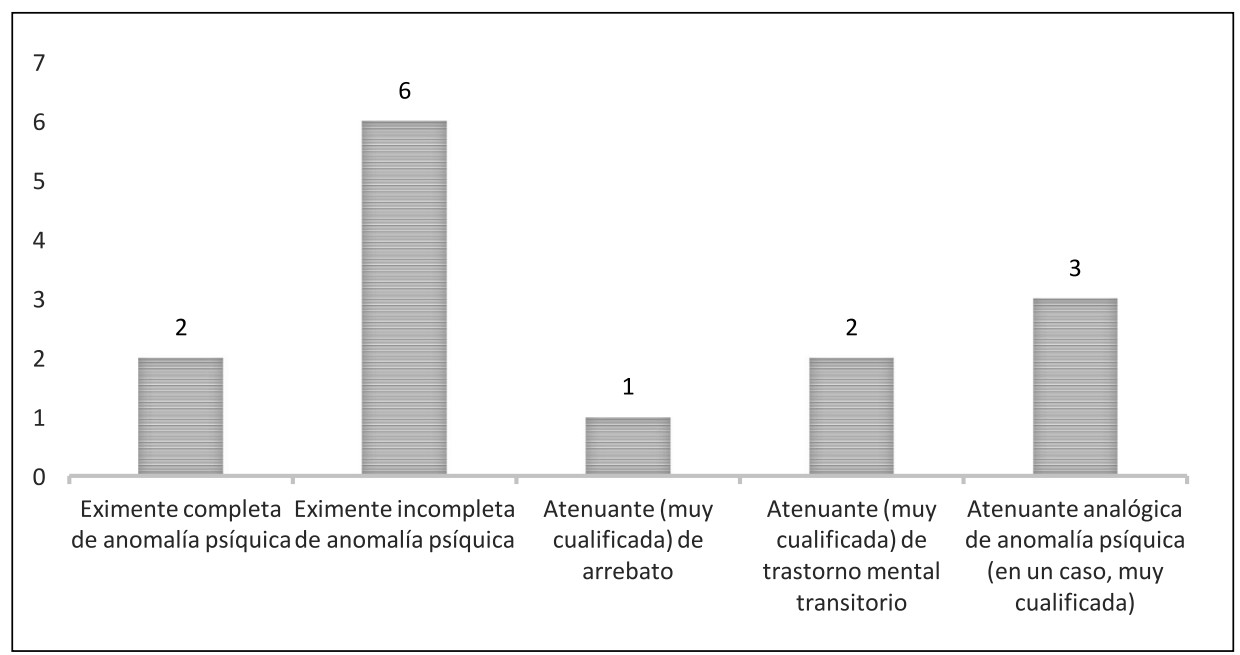

Fuente: Elaboración propia.

26 Sentencia del Tribunal Superior de Justicia de Cataluña de 29 de abril de 2010, Fundamento Jurídico $4{ }^{\circ}$. Esta sentencia revoca la previa sentencia condenatoria (en la que no se había apreciado alevosía), acogiéndose a la constante jurisprudencia del Tribunal supremo. "De hecho» - señala la sentencia- «no es posible descubrir más que una sola excepción a esta doctrina en la jurisprudencia del TS, que tiene una única excepción: la constituida por la ya antigua STS $2 .{ }^{\text {a }} 26$ abr. 1991 que - por cierto, en un delito de parricidio del CP 1973- excluyó la alevosía en la muerte de «un recién nacido, siempre carente de posibilidad de defensa», por ausencia del correspondiente «ánimo tendencial»» (ibidem). 
Pero más interesante, a mi juicio, que constatar algo que a priori parecía obvio, es observar la notable apreciación de eximentes (completas o incompletas) de inimputabilidad o atenuantes relacionadas con la situación psicológica de los progenitores, y, en especial, de las madres.

En efecto, en nada menos que 14 de las sentencias en procesos a madres por matar (o haber intentado matar) a sus hijos, se aplican eximentes o atenuantes de este tipo. Es decir, en un $41 \%$ de los casos totales. Además, del abanico de circunstancias posibles, llama la atención que la mayoría de ellas sean eximentes (completas o incompletas) o atenuantes muy cualificadas (con los efectos penológicos que esto tiene $e x$ artículo $66 \mathrm{CP}$ )

En cambio, no sucede lo mismo con los padres: sólo en dos supuestos se aprecia alguna circunstancia atenuante relacionada con su situación psicológica (un 9\% de los casos). En ambos supuestos, se aplica la atenuante análoga a alteración psíquica, y en ninguno de ellos se considera muy cualificada.

\section{Alguna conclusión (género y homicidio de menores) y algunos cabos sueltos}

Los problemas metodológicos expuestos en el apartado 2 son comunes a otros Estados. Por ejemplo, OBERMAN, quien utiliza un método muy similar al que plantea este trabajo, pero en el ámbito estadounidense, señala que «quizás el mayor problema para estudiar el infanticidio en América es encontrar un método sistemático para recopilar datos sobre su acaecimiento. La infradetección es un permanente problema a la hora de estimar la incidencia del infanticidio ${ }^{27}$. Acto seguido, la autora pone de manifiesto los problemas de una aproximación al fenómeno a través de resoluciones judiciales y la imposibilidad de obtener datos exhaustivos, concluyendo que «no obstante, recopilando datos sobre casos de infanticidio, al menos se puede identificar un fenómeno y demostrar que ocurre frecuentemente, si se muestra hasta qué punto los casos guardan similitudes entre sí» ${ }^{28}$.

Eso es exactamente lo que puede extraerse como (modesta) conclusión de este trabajo; hay (y siempre lo hubo ${ }^{29}$ ) un fenómeno, se da más

27 OBerman, M., «Mothers who kill: coming to terms with modern american infanticide», en DePaul Journal of Health Care Law, 8, 2004, p. 25.

28 OBERMAn, «Mothers who kill», cit., p. 26.

29 Sobre la muerte de menores a lo largo de la historia, Vid., entre otros, Moseley, K. L., "The history of infanticide in western society», en Issues in Law and Medicine, 1, 1986, pp. 345 y ss. o RAPAPORT, E., «Mad women and desperate girls: infanticide and child murder in Law and myth», en Fordham Urban Law Journal, 33, 2006, pp. 547 y ss.. 
de lo que sería deseable ${ }^{30}$ y puede ser agrupado con cierta facilidad en dos grandes grupos de casos: el de las mujeres que matan a sus hijos (en particular, a los recién nacidos) y el de los hombres que matan a menores en un contexto de violencia (física, psíquica o sexual) contra mujeres. Más de la mitad de los casos recogidos en la muestra jurisprudencial responden a alguna de esas dos categorías.

En este sentido, parece clara la existencia de una variable de género en el homicidio/asesinato de nuestros menores, variable que, en el caso de las mujeres, ha recibido gran atención legislativa y doctrinal en los últimos años.

En efecto, la sistemática existencia, en los Estados de nuestro entorno cultural, de un elevado número de mujeres que acaban con las vidas de sus hijos ${ }^{31}$ ha suscitado mucha literatura académica que ha intentado encontrar las razones y las dinámicas de ese dato incontrovertible ${ }^{32}$.

Aquí, por la propia naturaleza de este trabajo y su metodología, no entraremos en ese debate sociológico y criminológico sino en lo imprescindible para contextualizar los datos antes expuestos. Y, en esta línea, creo que lo más relevante es averiguar si el hecho de que sea la madre quien mata (o intenta matar) al menor influye en la percepción social (y jurídica) del hecho; si es cierto, como señala PEarson, que socialmente tendemos a considerar a los niños pequeños como meras extensiones de sus madres y, de algún modo, como algo que las madres poseen ${ }^{33}$.

Pues bien, distintos estudios ${ }^{34}$ ponen de manifiesto que los progenitores tienden a ser menos castigados por el homicidio de sus hijos que las personas ajenas al círculo familiar de los menores ${ }^{35}$; y, dentro del primer

${ }^{30} \mathrm{Si}$ bien, con las consabidas cautelas, se puede decir que nuestro Estado no se da este fenómeno en la medida en que se da en otros, ni siquiera en el tramo de edad de hasta 1 año (que, recordemos, es el más victimizado). Si cruzamos los datos del INE con los del Servicio Nacional de Salud estadounidense, veremos que, en 2016, la tasa de homicidio en dicho tramo de edad en España fue de 0,18/100.000, por un 6,7/100.000 de los Estados Unidos (cifra esta última prácticamente idéntica a la del Reino Unido, como se menciona en nota 5).

31 Y mujeres de todos los estratos socioeconómicos y sociales (Vid., por todos, OBeRMAN, «Mothers who kill», cit., pp. 27 y ss.).

32 Dato que, por otra parte, como agudamente señala Collins, coloca en una incómoda posición a parte del pensamiento feminista (Collins, J. M., «Lady Madonna, children at your feet: the criminal justice system's romanticization of the parent-child relationship», en Iowa Law Review, 93, 2007, pp. 179 y ss.).

33 Pearson, P., When she was bad: violent women and the myth of innocence, Viking books, Nueva York, 1997, p. 89.

${ }^{34}$ Dawson, M., "Rethinking the boundaries of intimacy at the end of the century: the role of victim-defendant relationship in Criminal Justice decision-making over time», en Law \& Society Review, 38, 2004, pp. 105 y ss.; BAUMAN, «Rethinking the Unthinkable», cit., p. 145.

35 La comparación en nuestro Estado sería complicada de hacer, dada la existencia de la circunstancia agravante de parentesco. 
grupo, las madres menos que los padres ${ }^{36}$. Lo anterior, unido a la existencia de legislaciones específicas en materia de infanticidio en muchos países - con un sentido atenuante de las penas respecto del homicidio común ${ }^{37}$, y a que las madres suelen ver reducida su pena como resultado de haber alegado algún tipo de trastorno psicológico ${ }^{38}$, da cuenta de una profunda ambivalencia social y legal hacia la muerte de los menores a manos de sus progenitores.

En el debate anglosajón (quizás el más interesante —probablemente, por la elevadísima tasa de muertes intencionales de menores en esos Es$\operatorname{tados}^{39}$ ) sobre esto último se suele aludir a la dicotomía, en el imaginario colectivo, entre considerar a dichas mujeres como víctimas de una desesperada situación psicológica o, sencillamente, como malvadas («mad»o «bad» $\left.{ }^{40}\right)$. Y esta dicotomía entre la demonización y la patologización tiene, a juicio unánime de la doctrina, evidentes repercusiones en las resoluciones judiciales que afectan a mujeres en general y a madres en particular ${ }^{41}$.

Si dejamos a un lado el tema de la demonización (pues, al contrario de lo que sucede en Estados Unidos y en el Reino Unido, donde el foco mediático se pone en las mujeres ${ }^{42}$, en España la demonización pública de asesinos de menores se pone sistemáticamente en hombres $\left.{ }^{43}\right)$, la pa-

36 Morris, A. / WiLCZYNSKI, A., "Parents who kill their children», en Criminal Law Review, 31, 1993, pp. 31 y ss.

37 OBERMan destaca que en prácticamente todos los ordenamientos que incluyen un delito ad hoc de infanticidio éste es castigado con menos pena que el resto de homicidios. Vid. OBerman, «Mothers who kill», cit., p. 22

38 De hecho, algunos tipos penales de infanticidio aluden expresamente a esta circunstancia. Por ejemplo, paradigmáticamente, en la regulación del Reino Unido, cuya definición reza textualmente así:

"Where a woman by any wilful act or omission causes the death of her child being a child under the age of twelve months, but at the time of the act or omission the balance of her mind was disturbed by reason of her not having fully recovered from the effect of giving birth to the child or by reason of the effect of lactation consequent upon the birth of the child" (Infanticide Act de 1938 — reformada en 2009—, sección primera).

$39 \mathrm{Vid}$. nota 30.

40 Por usar la expresión del influyente trabajo de WiLCZYNSKI (WILCZYNSKI, A., «Images of women who kill their infants: the mad and the bad», en Women \& Criminal Justice, 2, 1991, pp. 71 y ss.).

41 En este sentido, pone de relieve Ryznar que, en los Estados Unidos, las condenas a madres por matar a sus hijos oscilan desde los 2 años de prisión a la pena de muerte. Mismos hechos, distintas percepciones. Vid. RYZnAR, M., "A crime of its own? A proposal for achieving greater sentencing consistency in neonaticide and infanticide cases», en University of San Francisco Law Review, 47, 2013, p. 461 (con abundante jurisprudencia en nota al pie de página 14).

42 RAPAPORT, «Mad women and desperate girls», cit., p. 547; Collins, «Lady Madonna, children at your feet», cit., p. 157.

${ }^{43}$ Ningún caso concerniente a una mujer autora ha concitado jamás la expectación mediática de los casos de José Bretón y sus hijos, Miguel Carcaño y Marta del Castillo, Santiago del Valle y la niña Mari Luz, el asesino de la katana y su familia, Antonio Anglés/ Miguel Ricart y las chicas de Alcàsser... 
tologización supone considerar a las mujeres como personas con menor capacidad de autodeterminación, lo que redunda en la perpetuación de su posición subordinada en nuestra cultura ${ }^{44} \mathrm{y}$ en el ethos que asociamos a la maternidad ${ }^{45}$, circunstancia vital ésta que cuenta con una ominosa presencia en la vida de las mujeres.

En efecto, como señala OBERMAN, es nuestra particular sensibilidad social respecto de las circunstancias de la maternidad la pieza que hace que encaje el rompecabezas de por qué tendemos a perdonar el infanticidio cuando entra una madre en juego ${ }^{46}$. Y ese encaje se hace a través de la idea de que una mujer que mata a un hijo es porque tiene algún tipo de problema psíquico. Así, «las mujeres que matan a sus hijos pueden ser percibidas como mentalmente enfermas. Es decir, dado que el mandato de maternidad sugiere que las mujeres son fuente inagotable de cuidados, una mujer que mata a su propio hijo está violando el estereotipo de feminidad, expresando comportamientos violentos que son tan inesperados como inaceptables en el marco de la feminidad tradicional» ${ }^{47}$.

En segundo lugar, la aplicación de atenuantes o eximentes basadas, de un modo u otro, en la - por usar la terminología penal continental - inimputabilidad sería, por tanto, un modo de hacer "coexistir cómodamente la violencia femenina con las nociones tradicionales de feminidad $»^{48} \mathrm{y}$, en concreto, con la idea mitológica de la madre abnegada que lo da todo por sus hijos sin pedir nada a cambio. Como señala LANG, considerar que todas las mujeres que matan a sus hijos tienen algún problema psicológico con independencia de que tal afirmación sea un retrato certero o no de la situación personal de las madres concretas demuestra «el profundo deseo de la sociedad de patologizar a las mujeres que actúan fuera de los márgenes tradicionales de la maternidad (...) y a ignorar dicho fenómeno» ${ }^{49}$.

44 Así lo percibe, respecto del conjunto de eximentes y atenuante aplicadas a mujeres con mayor asiduidad que a hombres, Coughlin, A., "Excusing women», en California Law Review, 82, 1994, p. 25. En la misma línea, pero centrándose en el tema de este trabajo, MORRISSEY, B., When women kill: questions of agency and subjectivity, Routledge, Londres/ Nueva York, 2003, p. 24.

${ }_{45}$ Por usar, en este caso, la expresión de MacFarlane, J. E., "Neonaticide and the ethos of maternity: traditional Criminal Law defenses and the novel síndrome», en Cardozo Women's Law Journal, 5, 1998, pp. 175 y ss.

46 OBerman, «Mothers who kill», cit., p. 75.

47 DunN, K. F. / CowAN, G. / Downs, D., "Effects of sex and race of perpetrator and method of killing on outcome judgments in a mock filicide case», en Journal of applied social psychology, 36, 2016, p. 2397.

48 Stangle, H. L., "Murderous madonna: feminity, violence, and the myth of postpartum mental disorder in cases of maternal infanticide and filicide», en William and Mary Law Review, 50, 2008, p. 709.

49 LANG, L. J., "To love the babe that milks me: infanticide and reconceiving the mother», en Columbia Journal of Gender and Law, 14, 2005, p. 140. 
El punto álgido del debate es, por supuesto, la exitosa alegación de la psicosis post-puerperal como elemento eximente o atenuante, algo que es visto con recelo por una parte de la doctrina anglosajona ${ }^{50} \mathrm{y}$ con satisfacción por otra ${ }^{51}$, con toda una gama de grises intermedia ${ }^{52}$.

De nuevo, no tomaré ninguna posición en un debate psiquiátrico que excede de mi formación, pero, como el lector habrá adivinado, sí que arrojaré todo el anterior conglomerado de ideas sobre la situación que se vislumbra en nuestro Estado a través de las sentencias recabadas.

En efecto, como expuse antes, es muy alto el porcentaje de madres a las que se les aplican eximentes o atenuantes vinculadas con su estado psicológico, algo que no sucede en el caso de los padres. Esto, como tantos otros aspectos del fenómeno aquí estudiado, nos conecta con la misma situación que hay en otros Estados y, por consiguiente, con el debate sobre cómo interpretar ese hecho: ¿ ¿son los problemas psicológicos de las madres causa eficiente de sus conductas homicidas? ¿o el hecho de que se les apliquen atenuantes es un reflejo patologizante de nuestras preconcepciones sociales sobre la maternidad y la violencia femenina?

Resulta difícil dar una respuesta clara a dichos interrogantes, por lo limitado de la muestra, pero llama poderosamente la atención el grado de aceptación que nuestros órganos jurisdiccionales (muchas veces, no lo olvidemos, Tribunales del Jurado) dan a las alegaciones de atenuantes/ eximentes por parte de mujeres, dado que aquéllas se realizan en igual medida por acusados de ambos sexos.

De hecho, un análisis más detallado de las sentencias en las que se aplican a madres dichas atenuantes/eximentes muestra que es inusual que los tribunales realicen una argumentación pormenorizada de por qué concurre la circunstancia en el caso concreto y en qué medida ha

${ }^{50}$ Por ejemplo, la propia Stangle, H. L., «Murderous madonna», cit., pp. 703 y ss. o Dobson, V. / Sales, B., «The science of infanticide and mental illness», en Psychology, Public Policy, and Law, 6, 1998, pp. 1098 y ss.

51 Entre otros muchos, ConNell, M., «The postpartum psychosis defense and feminism: more or less justice for women?», en The case western reserve Law Review, 53, 2002, pp. 162 y ss.; WoNG, A., «Filicide and mothers who suffer from postpartum mental disorders», en Michigan State University Journal of Medicine \& Law, 10, 2006, pp. 571 y ss. o BIENSTOCK, S. L., "Mothers who kill their children and postpartum psychosis», en Southwestern University Law Review, 32, 2003, pp. 461 y ss.

52 Así, las matizadas opiniones de WiLLs, A. D., "Neonaticide: the necessity of syndrome evidence when safe haven legislation falls short», en Temple Law Review, 77, 2004, pp. 1001 y ss. o Tovino, S. A., "Scientific understandings of postpartum illness: improving health Law and policy?», en Harvard Journal of Law \& Gender, 33, 2010, pp. 99 y ss., quien, creo que certeramente, pone el foco de atención sobre el hecho de que el approach científico tiende a presentar sus resultados como potencialmente falibles y provisionales, mientras que el legislador y los jueces no se plantean modificar sus decisiones acompasándose al devenir de los descubrimientos médicos sobre la psicosis postparto (Vid. Tovino, "Scientific understandings of postpartum illness», cit. p. 172). 
afectado a la autora del hecho ${ }^{53}$. Incluso, en una de ellas, procedente de un Tribunal del Jurado, el Magistrado-Presidente señala que la argumentación de la «íntima convicción» de los jurados es mínima ${ }^{54}$.

Sin embargo, me interesan más las sentencias que sí argumentan la concurrencia de las circunstancias antes señaladas, porque es en ellas en las que parece aflorar, en efecto, una concepción de los hechos mediatizada por ser una mujer (y una mujer madre) la autora.

Así, por ejemplo, la sentencia de la Audiencia Provincial de Tenerife de 20 de octubre de 2005 juzga el caso de una mujer que tenía una orden de alejamiento respecto de su expareja, a la que había amenazado con matar a su hijo en común si no reanudaban dicha relación. La mujer, viendo que el hombre no accedía a ello, y tras una discusión, se encaramó a un puente con su hijo de año y medio en brazos. A la llegada de la policía, amenazó con saltar al vacío (niño incluido), consiguiendo la fuerza policial impedírselo.

Pues bien, respecto de estos hechos (que, por otra parte, si los géneros estuviesen intercambiados, encajarían perfectamente en la arquetípica violencia de los hombres respecto de sus hijos), el Tribunal señala lo siguiente: «en el presente caso los médicos forenses señalaron, ratificando sus informes que no existía patología de base para darse un trastorno mental, presentando un cuadro ansioso-depresivo secundario a una situación de stress vivida, siendo responsable y consciente de lo que hace, y que la situación se debió a un cúmulo de cosas: lo vivido le llevó a un momento de ira y enfado, pudiendo producirse un «cortocircuito». Los agentes que declararon en el Plenario y Juan Antonio pusieron de relieve que Maribel se encontraba muy exaltada y fuera de sí» ${ }^{55}$.

Sobre esa (exigua) base, se le aplica la atenuante de arrebato como muy cualificada. No voy a especular con qué habría sucedido de ser el padre el que hubiese llevado a cabo esos mismos hechos ${ }^{56}$, pero sí des-

53 Por supuesto, también hay excepciones: entre otras, las sentencias de la Audiencia provincial de Madrid de 24 de abril de 2015 y de 3 de julio de 2017, en las que se da cumplida cuenta de los problemas psiquiátricos de las mujeres, sus ingresos hospitalarios, la diagnosis de acuerdo con el DSM, cómo les afectó todo ello en el momento de los hechos, etc.

54 «Su conclusión final [la de los jurados] está sustentada en prueba practicada en el juicio oral con sujeción a los principios de oralidad, contradicción e inmediación, no correspondiendo pues a este Magistrado-Presidente, dada las funciones que legalmente vienen atribuidas al mismo, entrar a analizar la corrección material de dicha íntima convicción, más allá de comprobar que se ha practicado prueba que la sustenta, y que los Jurados han exteriorizado mínimamente la razón de su decisión» (Sentencia de la Audiencia Provincial de Las Palmas de 9 de julio de 2013, Fundamento jurídico 4. ${ }^{\circ}$ ).

55 Sentencia de la Audiencia Provincial de Tenerife de 20 de octubre de 2005, fundamento jurídico 5. ${ }^{\circ}$. Destacado en cursiva mío.

56 Entre otras cosas, porque he analizado la cuestión de la aplicación de la atenuante de arrebato a violencia de los hombres contra las mujeres y lo cierto es que existe en mayor medida de lo que parece razonable (permítaseme la autocita: RAmos VÁzQUEZ, J. A., «Provocación femenina, violencia masculina y la mitología del feminicidio pasional», en Revista Aranzadi de Derecho y proceso penal, 27, 2011, pp. 311 y ss.). 
tacaría que una rebaja en un grado de la pena habría merecido mayores explicaciones.

Otro ejemplo de lo apuntado podría ser la Sentencia de la Audiencia Provincial de Melilla de 27 de septiembre de 2003, que aplicó la eximente incompleta de anomalía psíquica al caso de una madre que arrojó a su hijo de 12 días de edad desde la azotea de su casa, falleciendo por el impacto contra el asfalto, limitándose a señalar lo siguiente:

«De la pericial psiquiátrica se desprende que, descartada la existencia de una psicopatía, la única explicación de los hechos es que la acusada tuviera una depresión grave, lo que, unido a su personalidad primaria, con un bajo dintel ante situaciones de frustración (nuevo embarazo, graves problemas económicos y familiares), le produjo un estrechamiento del campo de la conciencia ${ }^{57}$.

He destacado en cursiva el inciso «descartada la existencia de una psicopatía, la única explicación de los hechos es que la acusada tuviera una depresión grave», pues podría ser un indicio de que, efectivamente, haya habido en esta sentencia una patologización de la conducta de la mujer, en la línea de lo que apuntaba antes. Parece que el silogismo judicial tenga como premisa mayor que, necesariamente, para que el hecho de que una madre haya matado a su hijo tenga una explicación, ha de haber algún tipo de desorden psiquiátrico.

Por supuesto, insisto, la muestra es demasiado pequeña como para sacar conclusiones en una cuestión tan compleja, máxime cuando se acude en un tercio de las sentencias a la idea de un «trastorno psicótico no especificado» (que, por su propia definición médica, no tiene unos contornos $\left.\operatorname{claros}^{58}\right)$.

No obstante, me gustaría concluir estas consideraciones con una sentencia que, creo, resume bien el problema: se trata de la sentencia de la Audiencia Provincial de Castellón de 7 de octubre de 2005.

Los hechos son, muy resumidamente, los siguientes: una mujer, que nunca había aceptado su embarazo, da a luz en el hospital, sin avisar al personal sanitario, sentada en el inodoro, dejando caer el feto en éste, el cual es encontrado minutos más tarde por las enfermeras, boca abajo y cubierto de papel higiénico.

57 Sentencia de la Audiencia Provincial de Melilla de 27 de septiembre de 2003, fundamento jurídico 3..$^{\circ}$.

${ }^{58}$ El DSM lo define así: «esta categoría incluye una sintomatología psicótica (p. ej., ideas delirantes, alucinaciones, lenguaje desorganizado, comportamiento catatónico o gravemente desorganizado) sobre la que no se dispone de una información adecuada para establecer un diagnóstico específico o acerca de la cual hay informaciones contradictorias, o trastornos con síntomas psicóticos que no cumplen los criterios para alguno de los trastornos psicóticos específicos». El primer ejemplo que se da es, precisamente, la psicosis postparto. 
Pues bien, a pesar de que no había sido alegado por la defensa (y, consecuentemente, no había habido práctica de prueba al respecto), se apreció a la mujer la atenuante analógica del art. $21.6 \mathrm{CP}$ en relación con el 21.1 CP y 20.1 CP, como muy cualificada. Esto motivó el voto particular de un magistrado, quien, aparte de rechazar la apreciación de oficio de la atenuante (y su consideración como muy cualificada), indica lo siguiente:

«En el caso actual, no se declara probada la existencia de un auténtico trastorno de la personalidad ni puede deducirse la presencia de una anomalía psíquica. Se aprecia por la mayoría que la acusada venía sufriendo un embarazo no deseado que trataba por todos los medios de ocultar, y que ello le producía tensión y ansiedad, que cuando se produce el parto alcanza una intensidad que condiciona de modo relevante su respuesta ante lo evidente, orientándola hacia el abandono del bebé nacido, como negando una vez lo que venía resistiéndose a aceptar.

Pero toda esta descripción no constituye ninguna anomalía psíquica ni, por supuesto, configura una circunstancia atenuante. Se afirma que su estado era tembloroso y de llanto, como "ida" refiere el doctor T. en el juicio, y que es la manifestación externa de esa "sobrecarga afectiva" a la que hacen alusión los forenses en el juicio como condicionante de su comportamiento, estado psicológico al que ya se habían referido en su informe como justificador de la conducta de la acusada.

Sin embargo, nada de cuanto se expone constituye una base biopatológica de la anomalía psíquica y desde luego no puede deducirse que no tuviera capacidad para conocer la ilicitud del hecho y de adecuar su conducta a esa comprensión, pues no en vano los médicos forenses señalan que la acusada "presenta conservadas las facultades volitivas y cognitivas" ${ }^{59}$.

La actitud del magistrado disidente me parece coherente con la práctica jurisprudencial en estos $\operatorname{casos}^{60} \mathrm{y}$ arroja el interrogante de hasta qué punto sus compañeros han estado influidos por el hecho de que lo sucedido (una tentativa de asesinato, como ellos mismos la califican) sea entre una madre y un hijo recién nacido. Es decir, hasta qué punto el fetiche cultural de la maternidad y sus circunstancias les ha servido de marco para comprender y calificar los hechos.

Todo lo anterior respecto a las madres, pero ¿qué hay de los padres - y de los hombres en general?

Lo que hay es lo siguiente: casi la mitad de los homicidios/asesinatos de menores llevados a cabo por padres/parejas de la madre lo han sido

59 Sentencia de la Audiencia Provincial de Castellón de 7 de octubre de 2005, voto particular.

${ }_{60}$ Quien haya visto muchos procesos penales estará de acuerdo conmigo en que es bastante insólito que un tribunal aprecie de oficio una atenuante relacionada con la imputabilidad de la acusada. 
en contextos de violencia contra la mujer; dos menores han sido asesinadas por sus propias parejas y otras cuatro por hombres que previamente habían llevado a cabo una agresión sexual contra ellas. Es decir, si el arquetipo básico de la mujer en el fenómeno aquí estudiado es el de madre que mata a sus hijos, el del hombre es el de quien lleva a cabo violencia (física, psíquica o sexual) contra mujeres. Mujeres, además, que pueden ser tanto parejas como exparejas, tanto convivientes como no convivientes, tanto conocidas como desconocidas.

Poco más se puede decir al respecto; como poco más se puede decir acerca de todos esos hombres (amplia mayoría respecto del total, como vimos en el apartado 3) que, sin ninguna relación familiar con la víctima, acaban con la vida de ésta, dado que los hombres cometemos el 90\% de homicidios dolosos / asesinatos y, lógicamente, que el autor sea un hombre en hechos derivados de la comisión de delitos patrimoniales, peleas entre bandas juveniles, etc., es estadísticamente normal.

Dicho lo anterior, no me queda más que recapitular: el apartado tercero de este trabajo he trazado una perspectiva descriptiva del fenómeno del homicidio/asesinato de menores, a la luz de las sentencias recabadas, y en el cuarto he procurado ofrecer algunas vías de análisis sobre la, a mi juicio, más llamativa característica de esta clase de hechos: el que, aun siendo el homicidio un terreno masculinizado, un $45 \%$ de los autores de muertes violentas de menores sean mujeres ${ }^{61}$ y cómo esto afecta a las decisiones judiciales.

No obstante, soy perfectamente consciente de las limitaciones de este estudio, tanto por todo lo comentado en el apartado segundo acerca de la cifra negra y el problemático acceso a los datos como, sobre todo, por mis propias carencias en el ámbito criminológico.

Por ello, espero que en el futuro se arroje más luz sobre los aspectos que aquí han podido ser sólo enunciados y que, merecen, sin duda, mayor atención: explorar las posibilidades de un acopio exhaustivo de datos, estudiar la intersección de este tema con la medicina (síndrome de muerte súbita infantil, psicosis postpuerperal...), analizar la imagen mediática de los autores de esta clase de hechos (y por qué a igualdad de hechos cometidos, existe una abrumadora presencia de hombres y apenas de mujeres), etc.

Huelga decir que todas esas aportaciones deberían tener como objetivo poder tomar las oportunas medidas de prevención, en particular en el ámbito familiar, pues, como señala Collins, «si vamos en serio con la protección de los niños, tenemos que reorientar nuestro pensamiento hacia el hogar» ${ }^{62}$.

61 Vid. apartado 3.2

62 Collins, «Lady Madonna, children at your feet», cit., p. 183. 
Anexo: Cuadros sinópticos de las sentencias recabadas ${ }^{63}$

\begin{tabular}{|c|c|c|c|c|}
\hline & $\begin{array}{c}\text { Sentencia } \\
72 / 2001 \\
\text { AP Murcia } \\
\end{array}$ & $\begin{array}{c}\text { Sentencia } \\
\text { 23/03/2001 } \\
\text { AP Granada } \\
\end{array}$ & $\begin{array}{c}\text { Sentencia } \\
21 / 2007 \\
\text { AP Ciudad Real } \\
\end{array}$ & $\begin{array}{c}\text { Sentencia } \\
38 / 2003 \\
\text { AP Melilla } \\
\end{array}$ \\
\hline $\begin{array}{l}\text { Edad de la } \\
\text { víctima }\end{array}$ & 11 años & 8 años & 15 años & Recién nacido \\
\hline Sexo autor & Masculino & Femenino & Masculino & Femenino \\
\hline $\begin{array}{l}\text { Relación entre } \\
\text { autor y víctima }\end{array}$ & Hermanos & Ninguna & Ninguna & Madre \\
\hline Antecedentes & $\begin{array}{c}\text { Sin } \\
\text { antecedentes }\end{array}$ & $\begin{array}{c}\text { Sin } \\
\text { antecedentes }\end{array}$ & $\begin{array}{c}\text { Sin } \\
\text { antecedentes }\end{array}$ & $\begin{array}{c}\text { Sin } \\
\text { antecedentes }\end{array}$ \\
\hline $\begin{array}{l}\text { Grado de } \\
\text { ejecución }\end{array}$ & Consumado & Consumado & Consumado & Consumado \\
\hline $\begin{array}{l}\text { Calificación de } \\
\text { los hechos }\end{array}$ & $\begin{array}{l}\text { Asesinato con } \\
\text { agravante de } \\
\text { parentesco } \\
\text { y eximente } \\
\text { incompleta de } \\
\text { enajenación } \\
\text { mental }\end{array}$ & $\begin{array}{l}\text { Homicidio con } \\
\text { eximente } \\
\text { completa de } \\
\text { alteración } \\
\text { psíquica }\end{array}$ & Homicidio & $\begin{array}{c}\text { Asesinato } \\
\text { con eximente } \\
\text { incompleta } \\
\text { de alteración } \\
\text { psíquica }\end{array}$ \\
\hline & $\begin{array}{c}\text { Sentencia } \\
05 / 07 / 2002 \\
\text { AP Zaragoza } \\
\end{array}$ & $\begin{array}{c}\text { Sentencia } \\
79 / 2004 \\
\text { AP Madrid }\end{array}$ & $\begin{array}{c}\text { Sentencia } \\
3 / 2003 \\
\text { AP Murcia }\end{array}$ & $\begin{array}{c}\text { Sentencia } \\
241 / 2005 \\
\text { AP Almería }\end{array}$ \\
\hline $\begin{array}{c}\text { Edad de la } \\
\text { víctima }\end{array}$ & Recién nacido & 14 años & 4 y 6 años & 7 años \\
\hline Sexo autor & Femenino & Femenino & Femenino & Femenino \\
\hline $\begin{array}{l}\text { Relación entre } \\
\text { autor y víctima }\end{array}$ & Madre & Vecina & Madre & Vecina \\
\hline Antecedentes & $\begin{array}{c}\text { Sin } \\
\text { antecedentes }\end{array}$ & $\begin{array}{c}\text { Sin } \\
\text { antecedentes }\end{array}$ & $\begin{array}{c}\text { Sin } \\
\text { antecedentes }\end{array}$ & $\begin{array}{c}\text { Sin } \\
\text { antecedentes }\end{array}$ \\
\hline $\begin{array}{l}\text { Grado de } \\
\text { ejecución }\end{array}$ & Tentativa & Tentativa & Consumado & Consumado \\
\hline $\begin{array}{l}\text { Calificación de } \\
\text { los hechos }\end{array}$ & $\begin{array}{l}\text { Tentativa de } \\
\text { asesinato } \\
\text { agravante por } \\
\text { parentesco } \\
\text { y atenuante } \\
\text { de alteración } \\
\text { psíquica }\end{array}$ & $\begin{array}{l}\text { Tentativa de } \\
\text { homicidio }\end{array}$ & $\begin{array}{l}\text { Doble asesinato } \\
\text { con agravante } \\
\text { de parentesco }\end{array}$ & $\begin{array}{l}\text { Asesinato con } \\
\text { alevosía y } \\
\text { ensañamiento }\end{array}$ \\
\hline
\end{tabular}

${ }^{63}$ El orden es cronológico de los hechos delictivos y no de dictado de la sentencia. 


\begin{tabular}{|c|c|c|c|c|}
\hline & $\begin{array}{c}\text { Sentencia } \\
2 / 2004 \\
\text { AP de Alicante }\end{array}$ & $\begin{array}{l}\text { Sentencia } \\
\text { 562/2004 AP } \\
\text { Madrid }\end{array}$ & $\begin{array}{c}\text { Sentencia } \\
\text { 15/06/2006 } \\
\text { AP Castellón }\end{array}$ & $\begin{array}{c}\text { Sentencia } \\
692 / 2005 \\
\text { AP Girona }\end{array}$ \\
\hline $\begin{array}{l}\text { Edad de la } \\
\text { víctima }\end{array}$ & 16 años & 4 años & 13 y 12 años & Un mes \\
\hline Sexo autor & Masculino & Femenino & Masculino & Masculino \\
\hline $\begin{array}{l}\text { Relación entre } \\
\text { autor y víctima }\end{array}$ & Ninguna & Madre & Ninguna & Padre \\
\hline Antecedentes & $\begin{array}{c}\text { Sin } \\
\text { antecedentes }\end{array}$ & No constan & $\begin{array}{c}\text { Sin } \\
\text { antecedentes }\end{array}$ & $\begin{array}{c}\text { Sin } \\
\text { antecedentes }\end{array}$ \\
\hline $\begin{array}{l}\text { Grado de } \\
\text { ejecución }\end{array}$ & Consumado & Consumado & Tentativa & Tentativa \\
\hline \multirow[t]{2}{*}{$\begin{array}{l}\text { Calificación de } \\
\text { los hechos }\end{array}$} & Asesinato & $\begin{array}{l}\text { Asesinato con } \\
\text { agravante de } \\
\text { parentesco } \\
\text { y atenuante } \\
\text { analógica de } \\
\text { alteración } \\
\text { mental }\end{array}$ & $\begin{array}{l}\text { Tres delitos } \\
\text { de homicidio } \\
\text { en grado de } \\
\text { tentativa }\end{array}$ & $\begin{array}{l}\text { Tentativa de } \\
\text { asesinato con } \\
\text { agravante de } \\
\text { parentesco } \\
\text { y atenuante } \\
\text { analógica de } \\
\text { alteración } \\
\text { mental }\end{array}$ \\
\hline & $\begin{array}{c}\text { Sentencia } \\
596 / 2003 \\
\text { AP Valencia } \\
\end{array}$ & $\begin{array}{c}\text { Sentencia } \\
\text { 177/2005 AP } \\
\text { Valencia } \\
\end{array}$ & $\begin{array}{c}\text { Sentencia } \\
29 / 2006 \\
\text { AP Ciudad Real }\end{array}$ & $\begin{array}{c}\text { Sentencia } \\
\text { 1/2006 AP } \\
\text { Ourense }\end{array}$ \\
\hline $\begin{array}{c}\text { Edad de la } \\
\text { víctima }\end{array}$ & Recién nacido & Dos meses & 17 años & 4 años \\
\hline Sexo autor & Femenino & Masculino & Masculinos & $\begin{array}{c}\text { Femenino y } \\
\text { masculino }\end{array}$ \\
\hline $\begin{array}{l}\text { Relación entre } \\
\text { autor y víctima }\end{array}$ & Madre & Padre & Ninguna & $\begin{array}{l}\text { Madre y pareja } \\
\text { madre }\end{array}$ \\
\hline Antecedentes & $\begin{array}{c}\text { Por delitos } \\
\text { contra la salud } \\
\text { pública }\end{array}$ & $\begin{array}{c}\text { Sin } \\
\text { antecedentes }\end{array}$ & $\begin{array}{l}\text { Obstrucción a la } \\
\text { justicia y robo } \\
\text { con fuerza }\end{array}$ & $\begin{array}{c}\text { Sin } \\
\text { antecedentes }\end{array}$ \\
\hline $\begin{array}{l}\text { Grado de } \\
\text { ejecución }\end{array}$ & Tentativa & Consumado & Consumado & Consumado \\
\hline $\begin{array}{l}\text { Calificación de } \\
\text { los hechos }\end{array}$ & $\begin{array}{l}\text { Tentativa de } \\
\text { asesinato con } \\
\text { agravante de } \\
\text { parentesco y } \\
\text { atenuante por } \\
\text { grave adicción a } \\
\text { las drogas }\end{array}$ & $\begin{array}{l}\text { Asesinato con } \\
\text { agravante de } \\
\text { parentesco }\end{array}$ & $\begin{array}{c}\text { Coautores } \\
\text { homicidio } \\
\text { agravado por } \\
\text { disfraz y abuso } \\
\text { de superioridad; } \\
\text { atenuante } \\
\text { analógica de } \\
\text { drogadicción }\end{array}$ & $\begin{array}{l}\text { Asesinato con } \\
\text { agravante de } \\
\text { parentesco en } \\
\text { concurso ideal } \\
\text { con agresión } \\
\text { sexual }\end{array}$ \\
\hline
\end{tabular}




\begin{tabular}{|c|c|c|c|c|}
\hline & $\begin{array}{c}\text { Sentencia } \\
\text { 07/10/2005 AP } \\
\text { Castellón }\end{array}$ & $\begin{array}{c}\text { Sentencia } \\
\text { 09/03/2006 AP } \\
\text { Gipuzkoa }\end{array}$ & $\begin{array}{c}\text { Sentencia } \\
283 / 2006 \\
\text { AP Tenerife }\end{array}$ & \begin{tabular}{|c|} 
Sentencia \\
09/07/2004 \\
Juzgado \\
Menores Alicante \\
\end{tabular} \\
\hline $\begin{array}{l}\text { Edad de la } \\
\text { víctima }\end{array}$ & Recién nacido & 15 años & 7 años & 13 años \\
\hline Sexo autor & Femenino & Masculino & Masculino & Masculino \\
\hline $\begin{array}{l}\text { Relación entre } \\
\text { autor y víctima }\end{array}$ & Madre & Ninguno & Padre & Ninguna \\
\hline Antecedentes & $\begin{array}{c}\text { Sin } \\
\text { antecedentes }\end{array}$ & $\begin{array}{c}\text { Sin } \\
\text { antecedentes }\end{array}$ & $\begin{array}{c}\text { Sin } \\
\text { antecedentes }\end{array}$ & No constan \\
\hline $\begin{array}{l}\text { Grado de } \\
\text { ejecución }\end{array}$ & Tentativa & Tentativa & Consumado & Consumado \\
\hline \multirow[t]{2}{*}{$\begin{array}{l}\text { Calificación de } \\
\text { los hechos }\end{array}$} & $\begin{array}{c}\text { Tentativa de } \\
\text { asesinato con } \\
\text { dolo eventual; } \\
\text { agravante } \\
\text { parentesco y } \\
\text { atenuante muy } \\
\text { cualificada } \\
\text { de alteración } \\
\text { psíquica }\end{array}$ & $\begin{array}{l}\text { Tentativa de } \\
\text { asesinato } \\
\text { con eximente } \\
\text { incompleta } \\
\text { de anomalía } \\
\text { psíquica }\end{array}$ & $\begin{array}{l}\text { Asesinato con } \\
\text { la agravante de } \\
\text { parentesco }\end{array}$ & $\begin{array}{c}\text { Asesinato y } \\
\text { dos delitos de } \\
\text { agresión sexual }\end{array}$ \\
\hline & $\begin{array}{c}\text { Sentencia } \\
\text { 20/10/2005 AP } \\
\text { Tenerife }\end{array}$ & $\begin{array}{l}\text { Sentencia } \\
\text { 20/01/2006 } \\
\text { AP Madrid } \\
\end{array}$ & $\begin{array}{c}\text { Sentencia } \\
27 / 2006 \\
\text { AP Murcia } \\
\end{array}$ & $\begin{array}{c}\text { Sentencia } \\
1 / 2006 \text { AP } \\
\text { Álava }\end{array}$ \\
\hline $\begin{array}{l}\text { Edad de la } \\
\text { víctima }\end{array}$ & Año y medio & 17 años & 15 años & 3 años \\
\hline Sexo autor & Femenino & Femenino & Masculino & Masculino \\
\hline $\begin{array}{l}\text { Relación entre } \\
\text { autor y víctima }\end{array}$ & Madre & $\begin{array}{c}\text { Familiares de ex } \\
\text { pareja }\end{array}$ & Pareja víctima & Padre \\
\hline Antecedentes & $\begin{array}{c}\text { Sin } \\
\text { antecedentes }\end{array}$ & $\begin{array}{l}\text { Delitos contra la } \\
\text { salud pública }\end{array}$ & $\begin{array}{c}\text { Sin } \\
\text { antecedentes }\end{array}$ & $\begin{array}{c}\text { Sí, no } \\
\text { computables }\end{array}$ \\
\hline $\begin{array}{l}\text { Grado de } \\
\text { ejecución }\end{array}$ & Tentativa & Tentativa & Consumado & Consumado \\
\hline $\begin{array}{l}\text { Calificación de } \\
\text { los hechos }\end{array}$ & $\begin{array}{l}\text { Tentativa de } \\
\text { asesinato con } \\
\text { atenuante de } \\
\text { arrebato muy } \\
\text { cualificada }\end{array}$ & $\begin{array}{l}\text { Tentativa de } \\
\text { homicidio con } \\
\text { atenuante de } \\
\text { obcecación y } \\
\text { confesión }\end{array}$ & $\begin{array}{l}\text { Asesinato con } \\
\text { la atenuante de } \\
\text { confesión }\end{array}$ & $\begin{array}{l}\text { Asesinato con } \\
\text { alevosía y } \\
\text { ensañamiento } \\
\text { agravante de } \\
\text { parentesco y } \\
\text { atenuante muy } \\
\text { cualificada de } \\
\text { drogadicción }\end{array}$ \\
\hline
\end{tabular}




\begin{tabular}{|c|c|c|c|c|}
\hline & $\begin{array}{c}\text { Sentencia } \\
\text { 02/06/2011 AP } \\
\text { Badajoz }\end{array}$ & $\begin{array}{c}\text { Sentencia } \\
\text { 116/2017 AP } \\
\text { Asturias }\end{array}$ & $\begin{array}{c}\text { Sentencia } \\
\text { 494/2006 AP } \\
\text { Alicante }\end{array}$ & $\begin{array}{c}\text { Sentencia } \\
\text { 36/2010 AP A } \\
\text { Coruña }\end{array}$ \\
\hline $\begin{array}{l}\text { Edad de la } \\
\text { víctima }\end{array}$ & 15 y 17 años & 1 año & 5 años & 5 años \\
\hline Sexo autor & Masculino & Masculino & Masculino & Femenino \\
\hline $\begin{array}{l}\text { Relación entre } \\
\text { autor y víctima }\end{array}$ & Ninguna & Pareja madre & Padre & Madre \\
\hline Antecedentes & $\begin{array}{c}\text { Sin } \\
\text { antecedentes }\end{array}$ & $\begin{array}{l}\text { Violencia de } \\
\text { género }\end{array}$ & $\begin{array}{c}\text { Sin } \\
\text { antecedentes }\end{array}$ & $\begin{array}{c}\text { Sin } \\
\text { antecedentes }\end{array}$ \\
\hline $\begin{array}{l}\text { Grado de } \\
\text { ejecución }\end{array}$ & Tentativa & Consumado & Consumado & Tentativa \\
\hline $\begin{array}{l}\text { Calificación de } \\
\text { los hechos }\end{array}$ & $\begin{array}{l}\text { Dos tentativas } \\
\text { de homicidio }\end{array}$ & $\begin{array}{l}\text { Asesinato con } \\
\text { agravante de } \\
\text { parentesco; a } \\
\text { la madre en } \\
\text { comisión con } \\
\text { omisión con } \\
\text { agravante de } \\
\text { parentesco }\end{array}$ & $\begin{array}{l}\text { Asesinato con } \\
\text { agravante de } \\
\text { parentesco }\end{array}$ & $\begin{array}{c}\text { Tentativa de } \\
\text { asesinato con } \\
\text { atenuante de } \\
\text { drogadicción } \\
\text { y agravante de } \\
\text { parentesco }\end{array}$ \\
\hline & $\begin{array}{c}\text { Sentencia } \\
73 / 2008 \\
\text { AP Asturias }\end{array}$ & $\begin{array}{c}\text { Sentencia } \\
22 / 2008 \\
\text { AP Ciudad Real }\end{array}$ & $\begin{array}{c}\text { Sentencia } \\
20 / 2009 \\
\text { AP Segovia }\end{array}$ & $\begin{array}{c}\text { Sentencia } \\
10 / 2010 \\
\text { TSJ Cataluña }\end{array}$ \\
\hline $\begin{array}{c}\text { Edad de la } \\
\text { víctima }\end{array}$ & 2 años & 4 años & 10 años & Año y medio \\
\hline Sexo autor & Masculino & Masculino & Masculino & Femenino \\
\hline $\begin{array}{l}\text { Relación entre } \\
\text { autor y víctima }\end{array}$ & Padre & Tío & Padre & Madre \\
\hline Antecedentes & $\begin{array}{c}\text { Sin } \\
\text { antecedentes }\end{array}$ & $\begin{array}{c}\text { Sin } \\
\text { antecedentes }\end{array}$ & $\begin{array}{c}\text { Sin } \\
\text { antecedentes }\end{array}$ & No constan \\
\hline $\begin{array}{l}\text { Grado de } \\
\text { ejecución }\end{array}$ & Tentativa & Consumado & Tentativa & Consumado \\
\hline $\begin{array}{l}\text { Calificación de } \\
\text { los hechos }\end{array}$ & $\begin{array}{l}\text { Tentativa de } \\
\text { asesinato con } \\
\text { agravante de } \\
\text { parentesco }\end{array}$ & $\begin{array}{l}\text { Asesinato con } \\
\text { atenuante de } \\
\text { confesión }\end{array}$ & $\begin{array}{l}\text { Tentativa de } \\
\text { asesinato con } \\
\text { agravante de } \\
\text { parentesco }\end{array}$ & $\begin{array}{l}\text { Asesinato con } \\
\text { la agravante } \\
\text { de parentesco } \\
\text { y atenuante } \\
\text { analógica de } \\
\text { trastorno mental } \\
\text { transitorio }\end{array}$ \\
\hline
\end{tabular}




\begin{tabular}{|c|c|c|c|c|}
\hline & $\begin{array}{c}\text { Sentencia } \\
1052 / 2008 \\
\text { AP Barcelona }\end{array}$ & $\begin{array}{c}\text { Sentencia } \\
\text { 06/03/2009 } \\
\text { AP Jaén }\end{array}$ & $\begin{array}{c}\text { Sentencia } \\
31 / 2009 \\
\text { AP Madrid }\end{array}$ & $\begin{array}{c}\text { Sentencia } \\
69 / 2010 \\
\text { AP Badajoz }\end{array}$ \\
\hline $\begin{array}{l}\text { Edad de la } \\
\text { víctima }\end{array}$ & 17 años & 17 años & 3 años & 3 años \\
\hline Sexo autor & Masculino & Masculino & Masculino & $\begin{array}{l}\text { Femenino y } \\
\text { Masculino }\end{array}$ \\
\hline $\begin{array}{l}\text { Relación entre } \\
\text { autor y víctima }\end{array}$ & Pareja & Padre & Abuelo & Padres \\
\hline Antecedentes & $\begin{array}{c}\text { Sin } \\
\text { antecedentes }\end{array}$ & $\begin{array}{c}\text { Sin } \\
\text { antecedentes }\end{array}$ & $\begin{array}{c}\text { Sin } \\
\text { antecedentes }\end{array}$ & $\begin{array}{c}\text { Sin } \\
\text { antecedentes }\end{array}$ \\
\hline $\begin{array}{l}\text { Grado de } \\
\text { ejecución }\end{array}$ & Tentativa & Tentativa & Tentativa & Consumado \\
\hline $\begin{array}{l}\text { Calificación de } \\
\text { los hechos }\end{array}$ & $\begin{array}{l}\text { Tentativa de } \\
\text { asesinato con } \\
\text { agravante de } \\
\text { parentesco }\end{array}$ & $\begin{array}{l}\text { Tentativa de } \\
\text { homicidio con } \\
\text { agravante de } \\
\text { parentesco }\end{array}$ & $\begin{array}{c}\text { Tentativa de } \\
\text { asesinato con } \\
\text { agravante de } \\
\text { parentesco } \\
\text { y eximente } \\
\text { incompleta } \\
\text { de alteración } \\
\text { psíquica }\end{array}$ & $\begin{array}{l}\text { Asesinato (al } \\
\text { padre por } \\
\text { homicidio en } \\
\text { comisión por } \\
\text { omisión) }\end{array}$ \\
\hline & $\begin{array}{c}\text { Sentencia } \\
120 / 2009 \\
\text { AP Guadalajara }\end{array}$ & $\begin{array}{c}\text { Sentencia } \\
08 / 2010 \\
\text { AP Huelva }\end{array}$ & $\begin{array}{c}\text { Sentencia } \\
55 / 2009 \\
\text { AP Madrid }\end{array}$ & $\begin{array}{c}\text { Sentencia } \\
\text { 99/2010 } \\
\text { AP Almería }\end{array}$ \\
\hline $\begin{array}{l}\text { Edad de la } \\
\text { víctima }\end{array}$ & Recién nacido & 5 años & 11 años & Recién nacido \\
\hline Sexo autor & Femenino & Masculino & Masculino & Femenino \\
\hline $\begin{array}{l}\text { Relación entre } \\
\text { autor y víctima }\end{array}$ & Madre & Ninguna & Pareja madre & Madre \\
\hline Antecedentes & $\begin{array}{c}\text { Sin } \\
\text { antecedentes }\end{array}$ & $\begin{array}{c}4 \text { condenas } \\
\text { por delitos de } \\
\text { abusos sexuales }\end{array}$ & $\begin{array}{l}\text { Por delito de } \\
\text { abuso sexual y } \\
\text { lesiones }\end{array}$ & $\begin{array}{c}\text { Sin } \\
\text { antecedentes }\end{array}$ \\
\hline $\begin{array}{l}\text { Grado de } \\
\text { ejecución }\end{array}$ & Tentativa & Consumado & Consumado & Tentativa \\
\hline $\begin{array}{l}\text { Calificación de } \\
\text { los hechos }\end{array}$ & $\begin{array}{l}\text { Tentativa de } \\
\text { asesinato }\end{array}$ & Asesinato & $\begin{array}{l}\text { Asesinato con } \\
\text { agravante de } \\
\text { parentesco y } \\
\text { atenuante de } \\
\text { confesión }\end{array}$ & $\begin{array}{c}\text { Tentativa de } \\
\text { asesinato con } \\
\text { agravante de } \\
\text { parentesco }\end{array}$ \\
\hline
\end{tabular}




\begin{tabular}{|c|c|c|c|c|}
\hline & $\begin{array}{c}\text { Sentencia } \\
14 / 2010 \\
\text { AP Navarra } \\
\end{array}$ & $\begin{array}{c}\text { Sentencia } \\
14 / 2010 \\
\text { AP Navarra } \\
\end{array}$ & $\begin{array}{c}\text { Sentencia } \\
97 / 2009 \\
\text { AP Las Palmas } \\
\end{array}$ & $\begin{array}{c}\text { Sentencia } \\
05 / 2010 \\
\text { AP Toledo }\end{array}$ \\
\hline $\begin{array}{c}\text { Edad de la } \\
\text { víctima }\end{array}$ & 8 y 3 años & 8 y 3 años & Recién nacido & 3 años \\
\hline Sexo autor & Femenino & Femenino & Femenino & Masculino \\
\hline $\begin{array}{l}\text { Relación entre } \\
\text { autor y víctima }\end{array}$ & Madre & Madre & Madre & Padre \\
\hline Antecedentes & $\begin{array}{c}\text { Sin } \\
\text { antecedentes }\end{array}$ & $\begin{array}{c}\text { Sin } \\
\text { antecedentes }\end{array}$ & $\begin{array}{c}\text { Sin } \\
\text { antecedentes }\end{array}$ & $\begin{array}{c}\text { Sin } \\
\text { antecedentes }\end{array}$ \\
\hline $\begin{array}{l}\text { Grado de } \\
\text { ejecución }\end{array}$ & Consumado & Tentativa & Tentativa & Tentativa \\
\hline $\begin{array}{l}\text { Calificación de } \\
\text { los hechos }\end{array}$ & $\begin{array}{l}\text { Dos asesinatos } \\
\text { con agravante } \\
\text { de parentesco y } \\
\text { atenuante muy } \\
\text { cualificada de } \\
\text { trastorno mental } \\
\text { transitorio y } \\
\text { analógica de } \\
\text { reparación del } \\
\text { daño }\end{array}$ & $\begin{array}{l}\text { Dos tentativas } \\
\text { de asesinatos } \\
\text { con agravante } \\
\text { de parentesco y } \\
\text { atenuante muy } \\
\text { cualificada de } \\
\text { trastorno mental } \\
\text { transitorio y } \\
\text { analógica de } \\
\text { reparación del } \\
\text { daño }\end{array}$ & $\begin{array}{c}\text { Tentativa de } \\
\text { asesinato con } \\
\text { agravante de } \\
\text { parentesco } \\
\text { y eximente } \\
\text { incompleta } \\
\text { de alteración } \\
\text { psíquica }\end{array}$ & $\begin{array}{l}\text { Tentativa de } \\
\text { asesinato con } \\
\text { agravante de } \\
\text { parentesco y } \\
\text { atenuante de } \\
\text { reparación del } \\
\text { daño causado }\end{array}$ \\
\hline & $\begin{array}{c}\text { Sentencia } \\
03 / 2012 \\
\text { AP Islas } \\
\text { Baleares } \\
\end{array}$ & $\begin{array}{c}\text { Sentencia } \\
101 / 2010 \\
\text { AP Las Palmas }\end{array}$ & $\begin{array}{c}\text { Sentencia } \\
\text { 253/2009 } \\
\text { Juzgado Menores } \\
\text { Barcelona } \\
\end{array}$ & $\begin{array}{c}\text { Sentencia } \\
234 / 2012 \\
\text { AP Gipuzkoa }\end{array}$ \\
\hline $\begin{array}{c}\text { Edad de la } \\
\text { víctima }\end{array}$ & 9 años & 12 años & 14-15 años & 16 años \\
\hline Sexo autor & Femenino & Masculino & Masculino & Femenino \\
\hline $\begin{array}{l}\text { Relación entre } \\
\text { autor y víctima }\end{array}$ & Madre & Amigo del padre & $\begin{array}{c}\text { Compañeros de } \\
\text { clase }\end{array}$ & Madre \\
\hline Antecedentes & $\begin{array}{c}\text { Sin } \\
\text { antecedentes }\end{array}$ & $\begin{array}{c}\text { Sin } \\
\text { antecedentes }\end{array}$ & $\begin{array}{c}\text { Uno de ellos por } \\
\text { lesiones }\end{array}$ & No constan \\
\hline $\begin{array}{l}\text { Grado de } \\
\text { ejecución }\end{array}$ & Consumado & Consumado & Consumado & Tentativa \\
\hline $\begin{array}{l}\text { Calificación de } \\
\text { los hechos }\end{array}$ & $\begin{array}{l}\text { Asesinato con } \\
\text { agravante de } \\
\text { parentesco }\end{array}$ & $\begin{array}{l}\text { Allanamiento } \\
\text { de morada, } \\
\text { agresión sexual } \\
\text { y asesinato }\end{array}$ & $\begin{array}{l}\text { Asesinato con } \\
\text { alevosía y } \\
\text { ensañamiento; } \\
\text { otro asesinato } \\
\text { alevoso }\end{array}$ & $\begin{array}{c}\text { Tentativa de } \\
\text { homicidio con } \\
\text { agravante de } \\
\text { parentesco } \\
\text { y atenuante } \\
\text { analógica de } \\
\text { trastorno mental } \\
\text { por alcoholismo }\end{array}$ \\
\hline
\end{tabular}




\begin{tabular}{|c|c|c|c|c|}
\hline & $\begin{array}{c}\text { Sentencia } \\
1 / 2012 \\
\text { AP Sevilla }\end{array}$ & $\begin{array}{c}\text { Sentencia } \\
\text { 53/2010 AP } \\
\text { Burgos }\end{array}$ & $\begin{array}{c}\text { Sentencia } \\
4 / 2011 \\
\text { AP Sevilla }\end{array}$ & $\begin{array}{l}\text { Sentencia } \\
\text { 391/2012 AP } \\
\text { Girona }\end{array}$ \\
\hline $\begin{array}{l}\text { Edad de la } \\
\text { víctima }\end{array}$ & 17 años & 3 años & Recién nacido & 1 y 6 años \\
\hline Sexo autor & Masculino & Femenino & $\begin{array}{l}\text { Masculino y } \\
\text { Femenino }\end{array}$ & Femenino \\
\hline $\begin{array}{l}\text { Relación entre } \\
\text { autor y víctima }\end{array}$ & Amigo & Madre & Padres & Madre \\
\hline Antecedentes & $\begin{array}{c}\text { Sin } \\
\text { antecedentes }\end{array}$ & $\begin{array}{c}\text { Sin } \\
\text { antecedentes }\end{array}$ & $\begin{array}{l}\text { Padre: sí, no } \\
\text { computables; } \\
\text { Madre: no }\end{array}$ & $\begin{array}{c}\text { Sin } \\
\text { antecedentes }\end{array}$ \\
\hline $\begin{array}{l}\text { Grado de } \\
\text { ejecución }\end{array}$ & Consumado & Consumado & Consumado & Consumado \\
\hline $\begin{array}{l}\text { Calificación de } \\
\text { los hechos }\end{array}$ & Asesinato & $\begin{array}{l}\text { Asesinato con } \\
\text { agravante de } \\
\text { parentesco }\end{array}$ & $\begin{array}{c}\text { Él: asesinato } \\
\text { con agravante } \\
\text { de parentesco; } \\
\text { Ella: homicidio } \\
\text { en comisión por } \\
\text { omisión }\end{array}$ & $\begin{array}{c}\text { Dos asesinatos } \\
\text { con agravante } \\
\text { de parentesco } \\
\text { y atenuante } \\
\text { de confesión } \\
\text { y analógica } \\
\text { de alteración } \\
\text { mental }\end{array}$ \\
\hline & $\begin{array}{c}\text { Sentencia } \\
6 / 2012 \\
\text { AP Barcelona }\end{array}$ & $\begin{array}{c}\text { Sentencia } \\
330 / 2011 \\
\text { AP Albacete }\end{array}$ & $\begin{array}{c}\text { Sentencia } \\
491 / 2013 \\
\text { AP Madrid }\end{array}$ & $\begin{array}{c}\text { Sentencia } \\
332 / 2012 \\
\text { AP Valladolid }\end{array}$ \\
\hline $\begin{array}{l}\text { Edad de la } \\
\text { víctima }\end{array}$ & Recién nacidos & Recién nacido & 4 años & 14,9 y 3 años \\
\hline Sexo autor & Femenino & Femenino & Femenino & Femenino \\
\hline $\begin{array}{l}\text { Relación entre } \\
\text { autor y víctima }\end{array}$ & Madre & Madre & Madre & Cuidadora \\
\hline Antecedentes & $\begin{array}{c}\text { Sin } \\
\text { antecedentes }\end{array}$ & $\begin{array}{c}\text { Sin } \\
\text { antecedentes }\end{array}$ & $\begin{array}{c}\text { Sin } \\
\text { antecedentes }\end{array}$ & $\begin{array}{c}\text { Sin } \\
\text { antecedentes }\end{array}$ \\
\hline $\begin{array}{l}\text { Grado de } \\
\text { ejecución }\end{array}$ & Consumado & Tentativa & Consumado & Consumado \\
\hline $\begin{array}{l}\text { Calificación de } \\
\text { los hechos }\end{array}$ & $\begin{array}{c}\text { Asesinato } \\
\text { alevoso con } \\
\text { agravante de } \\
\text { parentesco y } \\
\text { homicidio por } \\
\text { imprudencia } \\
\text { grave }\end{array}$ & $\begin{array}{l}\text { Tentativa de } \\
\text { asesinato }\end{array}$ & $\begin{array}{l}\text { Asesinato con } \\
\text { agravante de } \\
\text { parentesco }\end{array}$ & $\begin{array}{l}\text { Tres delitos de } \\
\text { asesinato }\end{array}$ \\
\hline
\end{tabular}




\begin{tabular}{|c|c|c|c|c|}
\hline & $\begin{array}{c}\text { Sentencia } \\
374 / 2013 \\
\text { AP Valencia }\end{array}$ & $\begin{array}{c}\text { Sentencia } \\
31 / 2013 \\
\text { AP Barcelona }\end{array}$ & $\begin{array}{c}\text { Sentencia } \\
1 / 2013 \\
\text { AP Córdoba }\end{array}$ & $\begin{array}{c}\text { Sentencia } \\
3 / 2013 \\
\text { AP Segovia }\end{array}$ \\
\hline $\begin{array}{l}\text { Edad de la } \\
\text { víctima }\end{array}$ & 8 meses & 16 años & 6 y 2 años & Recién nacido \\
\hline Sexo autor & Masculino & Masculino & Masculino & Femenino \\
\hline $\begin{array}{c}\text { Relación } \\
\text { entre autor y } \\
\text { víctima }\end{array}$ & Pareja madre & Ninguna & Padre & Madre \\
\hline Antecedentes & No constan & $\begin{array}{c}\text { Sin } \\
\text { antecedentes }\end{array}$ & No constan & $\begin{array}{c}\text { Sin } \\
\text { antecedentes }\end{array}$ \\
\hline $\begin{array}{l}\text { Grado de } \\
\text { ejecución }\end{array}$ & Consumado & Consumado & Consumado & Consumado \\
\hline $\begin{array}{l}\text { Calificación } \\
\text { de los hechos }\end{array}$ & $\begin{array}{l}\text { Asesinato con } \\
\text { agravante de } \\
\text { parentesco }\end{array}$ & Asesinato & $\begin{array}{l}\text { Asesinato con } \\
\text { agravante de } \\
\text { parentesco }\end{array}$ & $\begin{array}{l}\text { Asesinato con } \\
\text { agravante de } \\
\text { parentesco } \\
\text { y atenuante } \\
\text { analógica de } \\
\text { confesión }\end{array}$ \\
\hline & $\begin{array}{c}\text { Sentencia } \\
157 / 2017 \\
\text { AP Gipuzkoa } \\
\end{array}$ & $\begin{array}{c}\text { Sentencia } \\
263 / 2012 \\
\text { AP Jaén }\end{array}$ & $\begin{array}{c}\text { Sentencia } \\
215 / 2012 \\
\text { AP Almería }\end{array}$ & $\begin{array}{c}\text { Sentencia } \\
125 / 2015 \\
\text { AP Barcelona }\end{array}$ \\
\hline $\begin{array}{l}\text { Edad de la } \\
\text { víctima }\end{array}$ & 13 años & Recién nacido & Recién nacido & 16 años \\
\hline Sexo autor & Masculino & Femenino & Femenino & Masculinos \\
\hline $\begin{array}{l}\text { Relación } \\
\text { entre autor y } \\
\text { víctima }\end{array}$ & Padre & Madre & Madre & Ninguna \\
\hline Antecedentes & $\begin{array}{c}\text { Sin } \\
\text { antecedentes }\end{array}$ & $\begin{array}{c}\text { Sin } \\
\text { antecedentes }\end{array}$ & $\begin{array}{c}\text { Sin } \\
\text { antecedentes }\end{array}$ & $\begin{array}{c}\text { Sin } \\
\text { antecedentes }\end{array}$ \\
\hline $\begin{array}{l}\text { Grado de } \\
\text { ejecución }\end{array}$ & Consumado & Consumado & Consumado & Tentativa \\
\hline $\begin{array}{l}\text { Calificación } \\
\text { de los hechos }\end{array}$ & $\begin{array}{l}\text { Asesinato con } \\
\text { agravante de } \\
\text { parentesco }\end{array}$ & $\begin{array}{l}\text { Asesinato con } \\
\text { agravante de } \\
\text { parentesco }\end{array}$ & $\begin{array}{l}\text { Asesinato con } \\
\text { agravante } \\
\text { de abuso de } \\
\text { superioridad }\end{array}$ & $\begin{array}{c}\text { Dos tentativas } \\
\text { de asesinato; en } \\
\text { uno concurre } \\
\text { eximente } \\
\text { incompleta } \\
\text { de alteración } \\
\text { psíquica }\end{array}$ \\
\hline
\end{tabular}




\begin{tabular}{|c|c|c|c|c|}
\hline & $\begin{array}{c}\text { Sentencia } \\
19 / 2015 \\
\text { AP Barcelona }\end{array}$ & $\begin{array}{c}\text { Sentencia } \\
43 / 2013 \\
\text { AP Las Palmas }\end{array}$ & $\begin{array}{c}\text { Sentencia } \\
\text { 76/2015 AP } \\
\text { Madrid }\end{array}$ & $\begin{array}{c}\text { Sentencia } \\
23 / 2015 \\
\text { AP Cuenca }\end{array}$ \\
\hline $\begin{array}{l}\text { Edad de la } \\
\text { víctima }\end{array}$ & 11 meses & Recién nacido & $\begin{array}{l}\text { Recién nacido y } \\
\quad 3 \text { años }\end{array}$ & Recién nacido \\
\hline Sexo autor & Masculino & Femenino & Masculino & Femenino \\
\hline $\begin{array}{l}\text { Relación entre } \\
\text { autor y víctima }\end{array}$ & Pareja madre & Madre & Compañero piso & Abuela \\
\hline Antecedentes & $\begin{array}{c}\text { Sin } \\
\text { antecedentes }\end{array}$ & $\begin{array}{c}\text { Sin } \\
\text { antecedentes }\end{array}$ & $\begin{array}{c}\text { Sí, no } \\
\text { computables }\end{array}$ & $\begin{array}{c}\text { Sí, no } \\
\text { computables }\end{array}$ \\
\hline $\begin{array}{l}\text { Grado de } \\
\text { ejecución }\end{array}$ & Consumado & Consumado & Consumado & Consumado \\
\hline \multirow[t]{2}{*}{$\begin{array}{l}\text { Calificación de } \\
\text { los hechos }\end{array}$} & $\begin{array}{l}\text { Asesinato con } \\
\text { atenuantes muy } \\
\text { cualificadas de } \\
\text { reparación y } \\
\text { confesión }\end{array}$ & $\begin{array}{l}\text { Asesinato } \\
\text { con eximente } \\
\text { completa de } \\
\text { alteración } \\
\text { psíquica }\end{array}$ & $\begin{array}{l}\text { Dos asesinatos } \\
\text { con eximente } \\
\text { incompleta } \\
\text { de anomalía } \\
\text { psíquica }\end{array}$ & $\begin{array}{c}\text { Asesinato con } \\
\text { circunstancia } \\
\text { mixta de } \\
\text { parentesco }\end{array}$ \\
\hline & $\begin{array}{c}\text { Sentencia } \\
\text { 7/2015 } \\
\text { AP Tenerife }\end{array}$ & $\begin{array}{c}\text { Sentencia } \\
34 / 2016 \\
\text { AP Barcelona }\end{array}$ & $\begin{array}{c}\text { Sentencia } \\
310 / 2015 \\
\text { AP Madrid }\end{array}$ & $\begin{array}{c}\text { Sentencia } \\
23 / 2014 \\
\text { AP A Coruña }\end{array}$ \\
\hline $\begin{array}{l}\text { Edad de la } \\
\text { víctima }\end{array}$ & 4 años & 15 años & Recién nacido & 13 años \\
\hline Sexo autor & Masculino & Masculino & Femenino & $\begin{array}{l}\text { Masculino y } \\
\text { Femenino }\end{array}$ \\
\hline $\begin{array}{l}\text { Relación entre } \\
\text { autor y víctima }\end{array}$ & Padre & Amigo & Madre & Padres \\
\hline Antecedentes & No constan & $\begin{array}{c}\text { Sin } \\
\text { antecedentes }\end{array}$ & $\begin{array}{c}\text { Sin } \\
\text { antecedentes }\end{array}$ & $\begin{array}{c}\text { Sin } \\
\text { antecedentes }\end{array}$ \\
\hline $\begin{array}{l}\text { Grado de } \\
\text { ejecución }\end{array}$ & Consumado & Consumado & Consumado & Consumado \\
\hline $\begin{array}{l}\text { Calificación de } \\
\text { los hechos }\end{array}$ & $\begin{array}{l}\text { Asesinato con } \\
\text { agravante de } \\
\text { parentesco y } \\
\text { atenuantes } \\
\text { de confesión } \\
\text { y analógica } \\
\text { de alteración } \\
\text { psíquica }\end{array}$ & $\begin{array}{l}\text { Homicidio } \\
\text { con agravante } \\
\text { de abuso de } \\
\text { superioridad }\end{array}$ & $\begin{array}{c}\text { Asesinato } \\
\text { con eximente } \\
\text { incompleta } \\
\text { de anomalía } \\
\text { psíquica, y } \\
\text { circunstancias } \\
\text { de confesión, } \\
\text { reparación y } \\
\text { parentesco }\end{array}$ & $\begin{array}{l}\text { Asesinato con } \\
\text { agravante de } \\
\text { parentesco }\end{array}$ \\
\hline
\end{tabular}




\begin{tabular}{|c|c|c|c|c|}
\hline & $\begin{array}{c}\text { Sentencia } \\
3 / 2016 \\
\text { AP Málaga }\end{array}$ & $\begin{array}{c}\text { Sentencia } \\
\text { 382/2015 AP } \\
\text { Alicante } \\
\end{array}$ & $\begin{array}{c}\text { Sentencia } \\
91 / 2015 \\
\text { AP Islas Baleares } \\
\end{array}$ & $\begin{array}{c}\text { Sentencia } \\
178 / 2015 \\
\text { AP Madrid }\end{array}$ \\
\hline $\begin{array}{c}\text { Edad de la } \\
\text { víctima }\end{array}$ & 7 años & 5 años & 6 años & 1 año \\
\hline Sexo autor & Masculino & Femenino & Masculino & Masculino \\
\hline $\begin{array}{l}\text { Relación entre } \\
\text { autor y víctima }\end{array}$ & Padre & Cuidadora & Padre & Padre \\
\hline Antecedentes & $\begin{array}{c}\text { Sí, no } \\
\text { computables }\end{array}$ & $\begin{array}{c}\text { Sí, no } \\
\text { computables } \\
\text { (maltrato } \\
\text { familiar, } \\
\text { quebrantamiento, } \\
\text { amenazas, } \\
\text { atentado a la } \\
\text { autoridad y } \\
\text { lesiones) } \\
\end{array}$ & $\begin{array}{c}\text { Sin } \\
\text { antecedentes }\end{array}$ & $\begin{array}{c}\text { Sí, no } \\
\text { computables }\end{array}$ \\
\hline $\begin{array}{l}\text { Grado de } \\
\text { ejecución }\end{array}$ & Consumado & Consumado & Tentativa & Consumado \\
\hline \multirow[t]{2}{*}{$\begin{array}{l}\text { Calificación de } \\
\text { los hechos }\end{array}$} & $\begin{array}{l}\text { Asesinato con } \\
\text { agravante de } \\
\text { parentesco }\end{array}$ & $\begin{array}{l}\text { Homicidio } \\
\text { con agravante } \\
\text { de abuso de } \\
\text { superioridad }\end{array}$ & $\begin{array}{c}\text { Tentativa de } \\
\text { asesinato con } \\
\text { agravante de } \\
\text { parentesco }\end{array}$ & $\begin{array}{l}\text { Asesinato con } \\
\text { agravante de } \\
\text { parentesco }\end{array}$ \\
\hline & $\begin{array}{c}\text { Sentencia } \\
\text { 178/2015 AP } \\
\text { Madrid } \\
\end{array}$ & $\begin{array}{c}\text { Sentencia } \\
\text { 124/2017 AP } \\
\text { Madrid } \\
\end{array}$ & $\begin{array}{c}\text { Sentencia } \\
173 / 2015 \\
\text { AP Madrid } \\
\end{array}$ & $\begin{array}{c}\text { Sentencia } \\
217 / 2016 \\
\text { AP Valencia } \\
\end{array}$ \\
\hline $\begin{array}{c}\text { Edad de la } \\
\text { víctima }\end{array}$ & 5 años & 9 años & 2 años y 4 meses & Recién nacido \\
\hline Sexo autor & Masculino & Masculino & Femenino & Femenino \\
\hline $\begin{array}{l}\text { Relación entre } \\
\text { autor y víctima }\end{array}$ & Padre & Pareja madre & Madre & Madre \\
\hline Antecedentes & $\begin{array}{c}\text { Sí, no } \\
\text { computables }\end{array}$ & $\begin{array}{c}\text { Sí, no } \\
\text { computables }\end{array}$ & $\begin{array}{c}\text { Sin } \\
\text { antecedentes }\end{array}$ & $\begin{array}{c}\text { Sin } \\
\text { antecedentes }\end{array}$ \\
\hline $\begin{array}{l}\text { Grado de } \\
\text { ejecución }\end{array}$ & Tentativa & Consumado & Consumado & Tentativa \\
\hline $\begin{array}{l}\text { Calificación de } \\
\text { los hechos }\end{array}$ & $\begin{array}{l}\text { Tentativa de } \\
\text { asesinato con } \\
\text { agravante de } \\
\text { parentesco }\end{array}$ & $\begin{array}{l}\text { Asesinato con } \\
\text { agravante de } \\
\text { parentesco }\end{array}$ & $\begin{array}{l}\text { Asesinato con } \\
\text { agravante de } \\
\text { parentesco } \\
\text { y eximente } \\
\text { incompleta } \\
\text { de alteración } \\
\text { psíquica }\end{array}$ & $\begin{array}{c}\text { Tentativa de } \\
\text { asesinato con } \\
\text { agravante de } \\
\text { parentesco } \\
\text { y eximente } \\
\text { incompleta } \\
\text { de alteración } \\
\text { psíquica }\end{array}$ \\
\hline
\end{tabular}




\begin{tabular}{|c|c|c|c|c|}
\hline & $\begin{array}{c}\text { Sentencia } \\
\mathbf{4 2 0 / 2 0 1 7} \\
\text { AP Madrid }\end{array}$ & $\begin{array}{c}\text { Sentencia } \\
\mathbf{4 2 / 2 0 1 7} \\
\text { AP Pontevedra }\end{array}$ & $\begin{array}{c}\text { Sentencia } \\
\mathbf{4 2 / 2 0 1 7} \\
\text { AP Las Palmas }\end{array}$ & $\begin{array}{c}\text { Sentencia } \\
\mathbf{1 0 2 / 2 0 1 7} \\
\text { AP Madrid }\end{array}$ \\
\hline $\begin{array}{c}\text { Edad de la } \\
\text { víctima }\end{array}$ & Recién nacido & 5 y 9 años & Recién nacido & Un año \\
\hline Sexo autor & Femenino & Masculino & $\begin{array}{c}\text { Masculino y } \\
\text { Femenino }\end{array}$ & Masculino \\
\hline $\begin{array}{c}\text { Relación entre } \\
\text { autor y víctima }\end{array}$ & Madre & Padre & Padres & Padre \\
\hline Antecedentes & $\begin{array}{c}\text { Sin } \\
\text { antecedentes }\end{array}$ & $\begin{array}{c}\text { Sin } \\
\text { antecedentes }\end{array}$ & $\begin{array}{c}\text { Sin } \\
\text { antecedentes }\end{array}$ & $\begin{array}{c}\text { Sin } \\
\text { antecedentes }\end{array}$ \\
\hline $\begin{array}{c}\text { Grado de } \\
\text { ejecución }\end{array}$ & Tentativa & Consumado & Consumado & Tentativa \\
\hline $\begin{array}{c}\text { Calificación de } \\
\text { los hechos }\end{array}$ & $\begin{array}{c}\text { Tentativa de } \\
\text { asesinato } \\
\text { con eximente } \\
\text { completa de } \\
\text { anomalía } \\
\text { psíquica }\end{array}$ & $\begin{array}{c}\text { Dos delitos } \\
\text { de asesinato } \\
\text { agravado, con } \\
\text { agravante de } \\
\text { parentesco }\end{array}$ & $\begin{array}{c}\text { Asesinato en } \\
\text { comisión por } \\
\text { omisión }\end{array}$ & $\begin{array}{c}\text { Tentativa de } \\
\text { asesinato con } \\
\text { agravante de } \\
\text { parentesco } \\
\text { y atenuante de } \\
\text { reparación }\end{array}$ \\
\hline
\end{tabular}

\section{Bibliografía}

BaUman, C. A., «Rethinking the Unthinkable: A study of child homicides», en Criminal Reports, 5. época, 8, 1997, pp. 139 y ss.

BiENSTOCK, S. L., "Mothers who kill their children and postpartum psychosis», en Southwestern University Law Review, 32, 2003, pp. 461 y ss.

Brookman, F. / Nolan, J., «The Dark Figure of Infanticide in England and Wales: Complexities of Diagnosis», en Journal of Interpersonal Violence, 21 (7), 2006, p. 869 y ss.

ColLins, J. M., «Lady Madonna, children at your feet: the criminal justice system's romanticization of the parent-child relationship», en Iowa Law Review, 93, 2007, pp. 131 y ss.

Company, A. / Pajón, L. / Romo, J. / Soria, M. A., «Filicidio, infanticidio y neonaticidio: estudio descriptivo de la situación en España entre los años 2000-2010», en Criminalidad, 57 (3), 2015, pp. 91 y ss.

ConNELL, M., «The postpartum psychosis defense and feminism: more or less justice for women?», en The case western reserve Law Review, 53, 2002, pp. 143 y ss.

Coughlin, A., «Excusing women», en California Law Review, 82, 1994, pp. 1 y ss. 
Dawson, M., "Rethinking the boundaries of intimacy at the end of the century: the role of victim-defendant relationship in Criminal Justice decision-making over time», en Law \& Society Review, 38, 2004, pp. 105 y ss.

Dobson, V. / Sales, B., «The science of infanticide and mental illness», en Psychology, Public Policy, and Law, 6, 1998, pp. 1098 y ss.

DunN, K. F. / Cowan, G. / Downs, D., «Effects of sex and race of perpetrator and method of killing on outcome judgments in a mock filicide Case», en Journal of applied social psychology, 36, 2016, pp. 2395 y ss.

EMERY, J. L., "Child abuse, sudden infant death syndrome, and unexpected infant death", en American Journal of Diseases of Children, 147 (10), 1993, pp. 1097 y ss.

GolDENBERG, C. L., «Sudden infant death syndrome as a mask for murder: investigating and prosecuting infanticide», en Southwestern University Law Review, 28, 1999, p. 599 y ss.

Kaplan, D. S., «Who Are the Mothers Who Need Safe Haven Laws? An Empirical Investigation of Mothers Who Kill, Abandon, or Safely Surrender Their Newborns», en Wisconsin Journal of Law, Gender \& Society, 29, 2014, pp. 448 y ss.

LANG, L. J., "To love the babe that milks me: infanticide and reconceiving the mother», en Columbia Journal of Gender and Law, 14, 2005, pp. 114 y ss.

MacFarlane, J. E., «Neonaticide and the ethos of maternity: traditional Criminal Law defenses and the novel syndrome», en Cardozo Women's Law Journal, 5, 1998, pp. 175 y ss.

McClain, P. / Sacks, J. / Froehlke, R. / Ewigman, B., «Estimates of fatal child abuse and neglect: United States, 1979-88», en Pediatrics, 91, 1993, pp. 338 y ss.

Morris, A. / WiLCZYNSKI, A., "Parents who kill their children», en Criminal Law Review, 31, 1993, pp. 31 y ss.

MORRISSEY, B., When women kill: questions of agency and subjectivity, Routledge, Londres/Nueva York, 2003.

Moseley, K. L., «The history of infanticide in western society», en Issues in Law and Medicine, 1, 1986, pp. 345 y ss.

OBERMAN, M., «Mothers who kill: coming to terms with modern american infanticide», en DePaul Journal of Health Care Law, 8, 2004, pp. 3 y ss.

Pearson, P., When she was bad: violent women and the myth of innocence, Viking books, Nueva York, 1997.

Ramos Vázouez, J. A., «Provocación femenina, violencia masculina y la mitología del feminicidio pasional», en Revista Aranzadi de Derecho y proceso penal, 27, 2011, pp. 311 y ss. 
RAPAPORT, E., «Mad women and desperate girls: infanticide and child murder in Law and myth», en Fordham Urban Law Journal, 33, 2006, pp. 527 y ss.

RYZNAR, M., «A crime of its own? A proposal for achieving greater sentencing consistency in neonaticide and infanticide cases», en University of San Francisco Law Review, 47, 2013, pp. 459 y ss.

STANGLE, H. L., «Murderous madonna: feminity, violence, and the myt of postpartum mental disorder in cases of maternal infanticide and filicide», en William and Mary Law Review, 50, 2008, pp. 699 y ss.

Tovino, S. A., «Scientific understandings of postpartum illness: improving health Law and policy?», en Harvard Journal of Law \& Gender, 33, 2010, pp. 99 y ss.

WILCZYNSKI, A., «Images of women who kill their infants: the mad and the bad», en Women \& Criminal Justice, 2, 1991, pp. 71 y ss.

WilLs, A. D., «Neonaticide: the necessity of syndrome evidence when safe haven legislation falls short», en Temple Law Review, 77, 2004, pp. 1001 y ss.

WonG, A., «Filicide and mothers who suffer from postpartum mental disorders», en Michigan State University Journal of Medicine \& Law, 10, 2006, pp. 571 y ss. 


\section{COMENTARIOS DE JURISPRUDENCIA}


